\title{
Aerosol time-series measurements over the tropical Northeast Atlantic Ocean: dust sources, elemental composition and mineralogy
}

Matthew D. Patey ${ }^{1,2,3}$, Eric P. Achterberg ${ }^{1,2^{*}}$, Micha J. Rijkenberg ${ }^{1,4}$, Richard Pearce ${ }^{1}$

${ }^{1}$ Ocean and Earth Science, National Oceanography Centre Southampton, University of Southampton, SO14 3ZH Southampton, UK

2GEOMAR, Helmholtz Centre for Ocean Research, 24148 Kiel, Germany
${ }^{3}$ Department of Chemistry, University of Las Palmas of Gran Canaria, Las Palmas, Spain

${ }^{4}$ Royal Netherlands Institute for Sea Research, Den Burg, 1790 AB Texel, The Netherlands

*Corresponding author: eachterberg@geomar.de 


\section{Abstract}

The North Atlantic receives the largest dust loading of any of the world's oceans due to its proximity to North African deserts and prevailing wind patterns. The supply of biologically important trace elements and nutrients via aerosols has an important influence on biogeochemical processes and ecosystems in this ocean region. In this study we continuously sampled aerosols between July 2007 and July 2008 at the Cape Verde Atmospheric Observatory (CVAO), which is situated on an island group close to the North African continent and under the Saharan/Sahelian dust outflow path. The aim of our work was to investigate temporal variations in aerosol concentration, composition and sources in the Cape Verde region over a complete seasonal cycle, and for this purpose we undertook mineralogical and chemical (42 elements) analyses of the aerosol samples and air mass back-trajectory calculations. Aerosol samples were also collected during a research cruise in the (sub-) tropical Northeast Atlantic Ocean in January 2008.

The concentration of atmospheric Al, a proxy for mineral aerosol concentration, at CVAO was in the range $0.01-66.9 \mu \mathrm{g} \cdot \mathrm{m}^{-3}$ (maximum on $28-30$ January 2008 ) with a geometric mean of $0.76 \mu \mathrm{g} \cdot \mathrm{m}^{-3}$. It showed distinct seasonal variations, with enhanced Al concentrations in winter (geometric mean 1.3 $\mu \mathrm{g} \cdot \mathrm{m}^{-3}$ ), and lower concentrations in summer (geometric mean $0.48 \mu \mathrm{g} \cdot \mathrm{m}^{-3}$ ). These observations have been attributed to dust transport occurring in higher altitude air layers and mainly north of the Cape Verde during summer, whilst in winter the dust transport shifts south and occurs in the lower altitude trade winds with consequent greater influence on the Cape Verde region. The elemental composition of the aerosols closely agreed with mean upper crustal abundances, with the exception of elements with pronounced anthropogenic sources (e.g. Zn and $\mathrm{Pb}$ ) and major constituents of sea water ( $\mathrm{Na}$ and $\mathrm{Mg}$ ). 
Mineral analysis showed that clays were the most abundant mineral fraction throughout the whole sampling period, with an increase in quartz and clays during strong dust events and an associated decrease in calcite. This could have important implications for the estimation of release of for example Fe from mineral dust with clays having a higher Fe solubility than quartz.

The elemental composition and mineralogy of aerosol samples collected during the cruise were indistinguishable from those collected at the CVAO during the same period, although mean atmospheric Al was $65 \%$ higher at the CVAO than those measured on the ship due to the irregular and uneven nature of dust transport.

Air mass back-trajectories showed an important role for southern source regions of the North African deserts during summer, with $92.5 \%$ of the samples indicating a contribution from the Sahel. Significantly elevated ratios of $\mathrm{V}, \mathrm{Ni}, \mathrm{Cu}, \mathrm{Zn}, \mathrm{Cd}$ and $\mathrm{Pb}$ with $\mathrm{Al}$ were present in samples originating from the Sahel compared with samples with a more northerly origin. This was likely due to enhanced anthropogenic emissions related to the greater population densities in the Sahel compared with the less developed Saharan regions further north.

Ratios of other elements and trends in rare earth elements could however not be used to distinguish differences in source regions. Similar source material compositions, the mixing of dust from different regions during transport, and the pooling of samples over a 1-3 day collection period appears to have diluted specific signals from source regions.

\section{Introduction}


Aeolian dust forms an important source of iron (Fe) and other biologically important trace elements and nutrients to microbial organisms in the global surface ocean (Baker et al., 2007; Duce and Tindale, 1991; Jickells et al., 2005). Transport of dust from the Sahara and Sahel regions of northern Africa results in increased dissolved Fe concentrations in the North Atlantic Ocean (Measures et al., 2008; Rijkenberg et al., 2008; Rijkenberg et al., 2012; Sarthou et al., 2007; Ussher et al., 2013), which influences dinitrogen fixation (Mills et al., 2004; Moore et al., 2009; Rijkenberg et al., 2011; Schlosser et al., 2014) and the structure and functioning of microbial communities (Hill et al., 2010).

The importance of mineral dust as a source of trace elements and nutrients to the open ocean has stimulated research into its production, transport, deposition and subsequent dissolution in surface waters. Over the last two decades, satellite measurements have proved indispensable in the evaluation of dust sources and the provision of transport pathways. While they provide unparalleled spatial and temporal coverage of dust transport, it is however hard to extract quantitative information on aerosol concentration and composition from satellite observations. In-situ aerosol measurements are therefore essential to obtain accurate data (Mahowald et al., 2005). Due to the sporadic nature of dust transport, long-term measurements of aerosols, such as those made at Bermuda, Miami and in the Canary Islands (Gelado-Caballero et al., 2012; Prospero and Lamb, 2003; Trapp et al., 2010) are essential in order to build up a picture of dust fluxes and composition.

The chemical composition and mineralogy of transported dust can be used to identify the original source of the dust. Through a combination of mineralogical and geochemical measurements, Chavagnac et al. (2007) traced the source of mineral dust particles collected in sediment traps in the Northeast Atlantic to the Anti-Atlas Moroccan mountains. Furthermore, Muhs et al. (2010) identified the source of mineral particles in the soils of the Canary Islands to the Sahara and Sahel desert regions. Recent 
research indicated the importance of dust composition and mineralogy for trace metal solubility (Aguilar-Islas et al., 2010; Sholkovitz et al., 2012), which highlights the need to link dust samples to specific sources.

Tracing individual Northwest African dust storms to specific source regions may be complicated due to several factors. Desert dust undergoes a continual process of uplift and deposition, mixing soils and smoothing out differences between the original source rocks (Schütz and Sebert, 1987). During longrange transport, homogenisation of air masses and physical selection for particles of similar size and mineralogy results in the composition of the transported dust reflecting the average composition of a large source region (Guieu et al., 2002; Schütz and Sebert, 1987). In addition, air-masses from densely populated or industrialised areas are often mixed with air-masses transporting the mineral aerosols, further altering the chemical composition of the bulk aerosol (Chester et al., 1999).

Aerosols collected at long-term monitoring sites in Barbados and Miami showed a high degree of homogeneity in chemical composition of north African dust by the time it had crossed the Atlantic Ocean. African dust reaches the western Atlantic predominantly during the summer via complex easterly weather systems, which entrain material from a wide area and transport this at high altitude, resulting in large-scale mixing and homogenization (Carlson and Prospero, 1972; Prospero and Carlson, 1972; Trapp et al., 2010). Analysis of aerosol samples collected closer to the north African continent, however, is often able to distinguish dust from different source regions. Various studies, interpreted with the aid of air-mass back trajectory calculations, have detected distinct signatures from aerosols originating in different desert regions for samples collected over the Mediterranean (Guieu et al., 2002), at sites in Spain (Querol et al., 2007), on the Canary Islands (Moreno et al., 2006) and along the West African margin (Stuut et al., 2005). Sample collection over a 3-year period on the island of Sal (Cape 
Verde archipelago) allowed allocation to one of three African source regions (Chiapello et al., 1997)

(Figure 1). Distinct $\mathrm{Fe} / \mathrm{Ca}, \mathrm{K} / \mathrm{Ca}, \mathrm{Si} / \mathrm{Al}$ and $\mathrm{Ca} / \mathrm{Al}$ ratios were found for samples originating from each of these regions related to higher amounts of $\mathrm{Ca}$ and enhanced Si/Al ratios in northern Saharan soils (Chiapello et al., 1997). Further work on this dataset showed that the ratio of the clay minerals illite / kaolinite formed a good indicator of aerosol origin, due to the higher abundance of kaolinite in the Sahel and southern Sahara (Caquineau et al., 1998).

Situated within the main transport area of dust over the tropical North Atlantic, the Cape Verde Islands form an excellent location to study dust inputs to this ocean region. Aerosol measurements over the tropical Northeast Atlantic are limited in both spatial and temporal coverage, with observations restricted to occasional research cruises (Baker et al., 2006; Sarthou et al., 2003; Sholkovitz et al., 2012), land-based observations from the Canary Islands (Gelado-Caballero et al., 2012; Neuer et al., 2004) and a limited number of studies on Cape Verde (e.g. Chiapello et al., 1997; Chiapello et al., 1995; Fomba et al., 2013). In this article we present a continuously collected set of chemical aerosol measurements covering a complete seasonal cycle for 42 elements in the tropical Northeast Atlantic. It is one of very few sets of long term measurements in the area and is the first study in the eastern tropical North Atlantic to present a continuous set of chemical measurements over a full annual cycle. The dataset is supplemented with mineralogical analysis of a selected number of samples, enabling a rare opportunity to interpret mineral composition in conjunction with chemical composition. Furthermore, we present a unique set of concurrent measurements made during a research cruise in the vicinity of Cape Verde in January and February 2008, during which high aerosol dust concentrations were experienced, enabling the comparison of independent measurements of corresponding air-masses on land and at sea. 


\section{Methodology}

\subsection{Aerosol Sample Collection}

\subsubsection{Aerosol sampling approach}

Atmospheric aerosols (total suspended particles - TSP) were collected on $47 \mathrm{~mm}$ diameter, polypropylene (0.45 $\mu \mathrm{m}$ nominal pore-size, Sterlitech) and polycarbonate filters ( $0.4 \mu \mathrm{m}$ pore-size, Nuclepore). The polypropylene filters were used for leaching experiments to be reported in a separate article, while the polycarbonate filters were used to measure total chemical (via total acid digestion) and mineralogical composition (X-Ray Diffraction (XRD) analysis). The polycarbonate filters were cleaned before use by soaking overnight in $1 \mathrm{~mol}^{-1} \mathrm{~L}^{-1} \mathrm{HCl}$ solution (Romil, SpA grade) and then rinsed thoroughly with deionised water (MilliQ water, $>18.2{\mathrm{M} \Omega \mathrm{cm}^{-1}}^{-1}$ Millipore). The cleaned filters were subsequently dried in a class-100 laminar flow cabinet.

\subsubsection{Cape Verde Atmospheric Observatory}

Aerosol sampling was undertaken at the Cape Verde Atmospheric Observatory (CVAO) (Carpenter et al., 2010) in the period between 2 July 2007 and 11 July 2008. The CVAO is situated on the northwest coast of the island of São Vicente $\left(16^{\circ} 51^{\prime} \mathrm{N}, 24^{\circ} 52^{\prime} \mathrm{W}\right)$, around $800 \mathrm{~km}$ off the west-African coast. Contamination from potential local aerosol sources can be disregarded due to a very stable northeasterly wind direction at the site resulting in sampled air that had not crossed land for more than 900 $\mathrm{km}$ since leaving the African mainland.

A low-volume aerosol sampler was installed at the top of a $30 \mathrm{~m}$ high sampling tower at the CVAO. The system comprised two rotary vane vacuum pumps (Piccolino VTE 8, Gardner Denver Thomas) drawing air through two pairs of $47 \mathrm{~mm}$ filters (two polycarbonate and two polypropylene filters). 
Thermal mass flow meters (Top Trak 826, Sierra Instruments) monitored the flow rates of air through the filters. A data logger (built in-house) monitored the analogue electrical signal from the mass flow meters and recorded the data on a Compact Flash memory card. For each pair of sample lines, the same type of filter was used in order to achieve an even distribution of flow between the two filters.

Typical flow rates through each filter were ca. 30 standard L. $\mathrm{min}^{-1}$, but this decreased as the filters became loaded with dust, particularly for the polycarbonate filters. Filters were changed three times per week (more often during intense dust events) and stored in a freezer $\left(-20^{\circ} \mathrm{C}\right)$ prior to shipment to Southampton for analysis. Filter freezing was deemed necessary as sample solubility has been observed to decrease with storage time at room temperature, but not when filters were stored frozen (Buck et al., 2006). Direct comparisons of elemental measurements on samples obtained on the CVAO using our low volume collector and a high volume Berner Impactor aerosol collector from Prof. Herrmann (TROPOS, Leipzig, Germany) showed excellent agreement (Carpenter et al., 2010). Nevertheless, higher total Fe concentrations were observed on filters sampled during periods of high dust loadings using the low volume collector, compared with the total Fe in PM10 collected using the high volume system (Carpenter et al., 2010). This observation was attributed to a greater number of larger particles sampled using the low volume system which were not collected using the PM10 Berner sampler.

\subsubsection{Research cruise aboard RRS Discovery (D326)}

Aerosol samples were also collected during a research cruise aboard the RRS Discovery in the tropical and subtropical eastern North Atlantic. A total of 29 sets of samples were collected in the period between 8 January and 4 February 2008. The area covered during the cruise is shown in the cruise track in Figure 1. 
A low volume sampler similar to the system installed at the CVAO was constructed for ship-board use. This system also contained rotary vane vacuum pumps and thermal mass flow meters. In order to reduce the risk of sample contamination from the ship and minimise the quantity of sea spray reaching the filters, the sampler was located on the deck above the bridge, as near to the bow and as high above the sea surface as practicable. In addition, a Perspex shroud surrounding the filter holders was used to reduce the quantity of sea-spray reaching the filters. During periods of rainfall, the sampler was switched off to avoid contamination of the filters. To reduce further the risk of contamination from the ship's fume stacks, an automatic control system was incorporated to prevent sampling when the wind direction was from the stern or the wind speed dropped below a threshold value of $2 \mathrm{~m} \mathrm{~s}^{-1}$. Filters were generally changed every 24 hours and more frequently during a dust event. The samples were stored frozen $\left(-20^{\circ} \mathrm{C}\right)$ until analysis.

\subsection{Sample analysis}

\subsubsection{Total Acid Digestion}

A microwave-assisted acid digestion procedure was used to dissolve the aerosol particles (Anton Paar Multiwave 3000 Microwave). The digestion approach completely dissolved the aerosol samples together with the polycarbonate filter material, producing a solution suitable for inductively coupled plasma mass spectrometry (ICP-MS) analysis. To minimise contamination, all work was carried out in a class-1000 clean laboratory. All Teflon digestion vessels were cleaned before use by soaking overnight in a large beaker of ca. 6 mol. $\mathrm{L}^{-1} \mathrm{HCl}$ (AR Grade, Fisher) placed on top of a hot-plate set to ca. $150^{\circ} \mathrm{C}$. The Teflon-ware was subsequently rinsed with deionised water before soaking overnight in a large beaker of ca. 8 mol. $\mathrm{L}^{-1} \mathrm{HNO}_{3}$ (AR Grade, Fisher) heated on a hot-plate at $150{ }^{\circ} \mathrm{C}$. The apparatus was rinsed thoroughly and dried in a clean-air drying cabinet. 
Whole polycarbonate sample filters (half a filter for samples from the ship-board system) were placed in digestion vessels together with $3 \mathrm{ml}$ concentrated $\mathrm{HCl}$ (sub-boiling distilled, ca. 11.5 mol. $\mathrm{L}^{-1}$ ), 3 $\mathrm{ml}$ concentrated $\mathrm{HNO}_{3}$ (sub-boiling distilled, ca. 15.5 mol.L ${ }^{-1}$ ) and $2.5 \mathrm{ml}$ concentrated HF (SpA grade, Romil). A 60 min programme was used for the microwave procedure, during which the temperature was increased linearly to $160^{\circ} \mathrm{C}$ over the first $15 \mathrm{~min}$, held at that temperature for $35 \mathrm{~min}$ before a further linear temperature increase to $175^{\circ} \mathrm{C}$ during the final $10 \mathrm{~min}$ of the programme. During this process a pressure of approximately 18-19 bar was reached. Digested samples were transferred to $30 \mathrm{ml}$ Teflon pots and evaporated on a hot plate at $140^{\circ} \mathrm{C}$ until only ca. $0.5 \mathrm{ml}$ remained. To avoid the formation of insoluble fluorides, $0.25 \mathrm{ml}$ of perchloric acid (SpA grade, Romil) was added and evaporation continued, with the hot plate temperature increased to $170^{\circ} \mathrm{C}$ when the perchloric acid began to evaporate. $\mathrm{A}$ further aliquot of $0.25 \mathrm{ml}$ perchloric acid was added during the middle of this process before allowing the samples to evaporate to dryness. The residues were re-dissolved in $2 \% \mathrm{v} / \mathrm{v} \mathrm{HNO}_{3}$ (sub-boiling distilled, ca. $0.3 \mathrm{~mol}^{-1}$ ), transferred to pre-weighed, acid-washed $30 \mathrm{ml} \mathrm{low}$-density polyethylene (LDPE, Nalgene) bottles, diluted to ca. $20 \mathrm{ml}$ and weighed prior to analysis.

An acid-cleaned (unused) filter was digested with each batch of samples to verify the cleanliness of the procedure and to provide a filter blank for the procedure.

\subsubsection{Certified Reference Material (CRM)}

To verify the effectiveness of the digestion procedure, $20 \mathrm{mg}$ of a CRM (standard reference material 1648a; urban particulate matter, NIST, USA) was included with every batch of samples. As this reference material contains refractory fractions, but is not directly representative of mineral aerosols, a finely ground loess sediment was also analysed regularly. This material was used for the GeoPT13 inter- 
laboratory inter-comparison exercise organised by the International Association of Geoanalysts, and its composition determined accurately with the consensus values publicly available (Potts et al., 2003).

To compensate for sample inhomogeneity, reference materials usually specify a minimum certified mass, which can be $250 \mathrm{mg}$ or more and is often far greater than the amount of aerosol material typically collected on filters (Buck and Paytan, 2012; Morton et al., 2013). For the CRMs used in this work, the NIST 1648a CRM specifies that $5 \mathrm{mg}$ or more should be analysed, whereas in the case of the loess material, a minimum quantity is not specified. However, several of the participants of the intercomparison exercise obtained satisfactory results with $10-20 \mathrm{mg}$ of material (Potts et al., 2003). In this study, the estimated mass of material collected on the filters varied from $5 \mu \mathrm{g}$ to $3.8 \mathrm{mg}$, with a geometric mean of $0.55 \mathrm{mg}$. While this is $1-2$ orders of magnitude less than the $20 \mathrm{mg}$ of CRM used, this should not invalidate the use of a reference material since a smaller quantity of sample should be at least as soluble as the CRM, particularly if the composition of the two materials is similar.

Good elemental recoveries were obtained when comparing the measured values for the two reference materials with certified / consensus values. Mean recoveries were better than $90 \%$ for most elements, with values dropping to $74 \%$ for the heavier rare earth elements (Table 1 ).

\subsubsection{ICP-MS analysis}

Total elemental concentrations in the dust samples were obtained using an ICP-MS instrument (XSERIES 2, Thermo Fisher Scientific) in the standard configuration with an autosampler (ASX-510, Cetac). A total of 42 elements were determined simultaneously (see Table 1). Standard solutions were prepared from 5 international rock reference materials. In addition, synthetic standard solutions were prepared from certified single element standard solutions (Romil) for $\mathrm{Ga}, \mathrm{Ag}, \mathrm{Cd}$ and $\mathrm{Sn}$ due to poorly defined 
reference values for the rock standards. All sample and standard solutions were spiked with a final concentration of $50 \mu \mathrm{g} \cdot \mathrm{L}^{-1}$ Be and $20 \mu \mathrm{g} \cdot \mathrm{L}^{-1}$ In and Re to correct for instrumental drift. Mean instrumental blank values were in the range $<4.2 \times 10^{-9} \mu \mathrm{g} \cdot \mathrm{m}^{-3}$ to $4.2 \times 10^{-4} \mu \mathrm{g} \cdot \mathrm{m}^{-3}$, while mean digested filter blanks were in the range $1.2 \times 10^{-8} \mu \mathrm{g} \cdot \mathrm{m}^{-3}$ to $1.0 \times 10^{-2} \mu \mathrm{g} \cdot \mathrm{m}^{-3}$ and were higher than the instrumental blanks for most elements. Filter blank concentrations were typically less than $5 \%$ of sample values, with the notable exception of $\mathrm{Ni}, \mathrm{Cu}$ and $\mathrm{Zn}$, for which the blank concentration was approximately $10 \%$ of the geometric mean sample concentration. All sample values have been corrected for blank interference by subtracting the mean digestion blank values shown in Table 1.

\subsubsection{XRD Analysis}

For selected samples, XRD spectra of aerosol material on the polycarbonate filters were obtained to determine the relative abundance of different minerals in the dust. Samples were analysed on a Panalytical X'Pert pro diffractometer instrument fitted with a Cu X-ray tube. Operating conditions were $35 \mathrm{kV}, 40 \mathrm{~mA}$ with a step size of $0.02^{\circ} 2 \Theta$ and a scan rate of $0.308^{\circ} 2 \Theta /$ minute, and utilising $0.5^{\circ}$ fixed slits. Samples were carefully placed on a silicon disc and scanned from $2^{\circ} 2 \Theta$ through either $55^{\circ}$ or $76^{\circ}$ 2O. Spectra were processed using the Siroquant v2.6 software package to quantify the minerals present. Siroquant uses the Rietveld method to quantify absolute mineral abundances. It is a standard-less technique that uses crystal structural data and least squares refinement of Rietveld parameters to calculate an XRD pattern to match a sample XRD pattern, calculating the weight percent of sample mineralogy and compensating for preferred orientation of mineral grains. Relative errors of $\pm 3 \%$ are given for crystalline phases by Hillier (2000) using the Rietveld method, Hill et al. (1993) quote 2-7\% for phases with abundance $>15$ wt. $\%$, increasing to 10\% for phases at about 2 wt. $\%$, increasing further for 
phases at $<1 w t . \%$. Detection limits are of the order of $\pm 0.5-2 \%$ for crystalline phases, for clays precision values are $\pm 10-20 \%$ of the amount present, with corresponding clay ratio errors of $\pm 20-40 \%$.

\subsection{Back-trajectory Calculation}

Each sample was interpreted in terms of air-mass source by calculating five-day isentropic air-mass back-trajectories using the HYSPLIT (HYbrid Single-Particle Lagrangian Integrated Trajectory) model (Draxler, 1999; Draxler and Hess, 1997; Draxler and Hess, 1998) with the GDAS meteorological dataset. Trajectories were calculated for arrival heights of 30, 750, 1500, 2000, 2500 and $3000 \mathrm{~m}$ above the sampling location. In case of sample collection at the CVAO, trajectories were calculated for $12 \mathrm{~h}$ time intervals, finishing at $1200 \mathrm{~h}$ and $0000 \mathrm{~h} \mathrm{GMT}$. For samples collected during cruise D326, trajectories were calculated for the start and end of every sampling period, and if the sampling period was greater than $18 \mathrm{~h}$, a third trajectory was calculated for the mid-point of the sampling period.

\section{Results \& Discussion}

\subsection{Aerosol concentration and composition}

A summary of the data from the CVAO and cruise D326, including the range of concentrations with mean values and standard deviation for each element is presented in Table 2 . The full elemental data set is provided in the appendix. Previous studies have shown that aerosol datasets are log-normally distributed (Kok, 2011) and therefore the geometric mean corresponds with the modal concentration and facilitates comparison with other datasets. Application of the Kolmogorov-Smirnov to the combined CVAO and D326 datasets after log-transformation showed that the data fitted the normal distribution for 35 of the 42 elements measured by ICP-MS (all except $\mathrm{Na}, \mathrm{Mg}, \mathrm{K}, \mathrm{V}, \mathrm{Cr}$, Sr and $\mathrm{Ag}$ ). A visual inspection 
of the distributions that failed the test indicated that this was due to a small number of outliers at low concentrations or to slight deviations from normality, but that the underlying distribution was still lognormal.

Aluminium is used as a tracer for dust inputs into the ocean as it is not actively taken up by marine phytoplankton, and therefore dissolved Al has a relatively long residence time of $3-5$ years in surface seawaters (Orians and Bruland, 1986). The element is also frequently used as a tracer for mineral aerosol mass (Guieu et al., 2002; Hsu et al., 2010) due to its high crustal abundance of 8.04\% (Taylor and McLennan, 1995). It is possible to use other elements with predominantly crustal sources instead of Al as a tracer of mineral aerosol mass, and this is facilitated by the lower detection limits of modern ICP-MS instrumentation. Trapp et al. (2010) opted to use $\mathrm{Mn}$ as a crustal tracer after obtaining a stronger correlation between TSP (total suspended particles; obtained by weighing the filters before and after sampling) and $\mathrm{Mn}$ than between TSP and Al; an observation which the authors attributed to analytical problems (ICP-MS detector saturation) caused by the high Al concentrations in their samples.

No direct measurements of TSP mass were made during this study, and in the absence of any evidence that another element was better and to facilitate comparison with many previous studies, Al was chosen as a crustal tracer for this work. Moreover, our use of Al as a tracer is further justified by very strong correlations between Al and many other elements of predominantly mineral origin (e.g. for Al vs $M n: R^{2}=0.998$ and Al vs Fe: $\left.R^{2}=0.996, n=153\right)$. Furthermore, there was no evidence of detector saturation at high Al concentrations and Al recovery from CRMs was close to $100 \%$ (Table 1).

\subsubsection{Cape Verde Atmospheric Observatory}


Figure 2a shows total atmospheric concentrations of Fe and Al over the course of one year at the CVAO as well as the estimated aerosol concentrations derived from the Al data. Iron and Al in the aerosol samples were present in measurable quantities throughout the year at the CVAO site, but a number of periods with elevated aerosol concentration are apparent in the dataset. The data indicates a marked difference between summer and winter concentrations. Periods of elevated aerosol concentrations were more frequent and more intense during the winter months, with the highest concentrations observed during December 2007 and January 2008. Samples collected during the summer months (May-October) showed a geometric mean atmospheric Al concentration of $0.48 \mu \mathrm{g} . \mathrm{m}^{-3}$, whereas samples collected during the winter (November-April) showed a significantly higher geometric mean Al of $1.3 \mu \mathrm{g} \cdot \mathrm{m}^{-3}$ (student's t-test: $\mathrm{p}<0.001$ ). A seasonal pattern in dust concentrations on Cape Verde was also reported by Chiapello et al. $(1997 ; 1995)$ and linked to varying meteorological conditions related to seasonal shifts in the Intertropical Convergence Zone (ITCZ). In summer, the ITCZ is positioned at $6-10^{\circ} \mathrm{N}$ and dust is transported in the Saharan Air Layer (with a base at 1-1.5 km and a top to $5-7 \mathrm{~km}$ altitude) and therefore above the atmospheric layer of the trade winds, with consequently low dust concentrations on Cape Verde. The conditions in summer allow long-range transport of mineral dust to the western North Atlantic Ocean (e.g. Barbados and South Florida) (Prospero and Carlson, 1972), where dust concentrations are then at their maximum (Prospero and Lamb, 2003). In winter, dust transport occurs at lower altitudes in the trade wind layer below $1.5 \mathrm{~km}-3 \mathrm{~km}$ altitude and mineral dust concentrations over the eastern tropical and subtropical North Atlantic (including Cape Verde) are at their maximum. These conditions in winter are facilitated by a shift south of the ITCZ of up to $10^{\circ}$, and dust transport reaches South America (Prospero and Carlson, 1980).

\subsubsection{Research cruise RRS Discovery (D326) and comparison with CVAO}


During the research cruise aboard the RRS Discovery, two periods with enhanced airborne dust concentrations were encountered (Figure $2 \mathrm{~b}$ ). The first event was in the period from 17 to 22 January 2008 and a second more intense and prolonged dust event was encountered between 25 January and 1 February 2008. A MODIS true colour satellite image of the region around the time of peak dust concentrations on 30 January 2008 is shown in Figure 3 . There was a notable similarity between the peaks in aerosol Al concentrations observed aboard RRS Discovery and measured at CVAO during the corresponding period, although higher Al concentrations were measured at CVAO with peak concentrations $\left(66.9 \mu \mathrm{g} \cdot \mathrm{m}^{-3} \mathrm{Al}\right)$ almost twice the maximum shipboard values $\left(36.2 \mu \mathrm{g} \cdot \mathrm{m}^{-3} \mathrm{Al}\right)$. Mean Al concentrations for the two sets of measurements also showed higher values at the CVAO $\left(10.5 \mu \mathrm{g} \cdot \mathrm{m}^{-3} \mathrm{Al}\right.$ D326 vs $17.3 \mu \mathrm{g} \cdot \mathrm{m}^{-3} \mathrm{Al}$ CVAO).

An annual arithmetic mean atmospheric Al concentration of $2.9 \mu \mathrm{g} \cdot \mathrm{m}^{-3}$ was observed at CVAO between July 2007 and July 2008, while the arithmetic mean Al concentration between 7 January and 4 February 2008 (during cruise D326) at CVAO was $17.3 \mu \mathrm{g} \cdot \mathrm{m}^{-3}$. Using the upper crustal abundance (UCA) of $\mathrm{Al}$, this monthly arithmetic mean value (CVAO January 2008) corresponded to a theoretical mineral dust concentration of $214.9 \mu \mathrm{g} \cdot \mathrm{m}^{-3}$. Chiapello et al. (1995) reported maximum monthly mean mineral dust concentrations of 120, 95 and $70 \mu \mathrm{g} \cdot \mathrm{m}^{-3}$, for 1992, 1993 and 1994, respectively. An arithmetic mean shipboard concentration of $10.5 \mu \mathrm{g} \cdot \mathrm{m}^{-3} \mathrm{Al}$ was observed during the same period, which equates to 131 $\mu \mathrm{g} \cdot \mathrm{m}^{-3}$ mineral dust. Buck et al. (2010)(2010) recorded a peak of $5.95 \mu \mathrm{g} \cdot \mathrm{m}^{-3} \mathrm{Al}$ (corresponding to about $74 \mu \mathrm{g} . \mathrm{m}^{-3}$ dust) on 26 July 2003, during a research cruise passing ca. $200 \mathrm{~km}$ west of Cape Verde. Thus during January 2008 the observed dust loadings were high for the region.

Mean measured atmospheric Al concentrations observed at CVAO during the cruise period were $65 \%$ higher than the shipboard measurements. This can be explained by the difference in location of the 
vessel and the CVAO (RRS Discovery was sailing between 175 and $1050 \mathrm{~km}$ to the west/northwest of CVAO during the dust event of $25 \mathrm{Jan}-1 \mathrm{Feb}$ ) (see Figure 1 ) and is probably due to the ephemeral and heterogeneous nature of dust plumes. This heterogeneous nature is apparent in the satellite image in Figure 3. It is noteworthy that during the first half of this dust event, while the ship was sailing to the west of the Cape Verde Islands (less than $300 \mathrm{~km}$ from the CVAO), mean atmospheric Al concentrations were similar (one filter at CVAO covering $25-28$ January 2008 measured a value of $21.2 \mu \mathrm{g} \cdot \mathrm{m}^{-3} \mathrm{Al}$, while six filters covering a similar period on the ship led to atmospheric Al concentrations in the range $14.0-$ $32.0 \mu \mathrm{g} \cdot \mathrm{m}^{-3}$ with an average of $21.1 \mu \mathrm{g} \cdot \mathrm{m}^{-3}$ ). During the second half of the dust event, after the ship had moved north of the Cape Verde Islands (see Figure 1), aerosol Al concentrations experienced on the ship were significantly lower than at the CVAO.

A comparison was made between elemental abundances of 28 samples collected during the cruise (covering 8 January to 4 February 2008) with 11 samples from the CVAO (covering 7 January to 4 February 2008) that most closely matched the cruise period. Elemental concentrations were normalized by conversion to ratios with Al before applying student's t-test to compare the two sets of samples. With the exception of $\mathrm{Pb} / \mathrm{Al}$, no statistically significant differences were found, indicating that we were sampling the same dust plume. For $\mathrm{Pb}$, enhanced levels were found in the shipboard samples $(\mathrm{Pb} / \mathrm{Al}=$ 0.003, standard deviation $=0.005, \mathrm{n}=28)$ compared to those from CVAO $(\mathrm{Pb} / \mathrm{Al}=0.0008$, standard deviation $=0.001, \mathrm{n}=11$ ). One explanation for the higher $\mathrm{Pb}$ content and higher variability of the shipboard measurements is that it was the result of slight contamination from the ship's exhaust, which despite our best efforts to control (aerosol sampling conducted only whilst stack fumes were blown away from the position of the collector) was situated only $20 \mathrm{~m}$ from the sampling location. However, since no other elements typical of stack contamination were elevated relative to samples from CVAO, 
the difference may be due to the presence of more anthropogenic aerosols from continental sources in the shipboard samples.

\subsubsection{Enrichment factors}

The overall composition of the aerosols collected at both CVAO and during cruise D326 closely agreed with mean UCAs, with the exception of a limited number of elements (Figure 4). Elements with abundances significantly higher than UCA were either major constituents of seawater $(\mathrm{Na}, \mathrm{Mg})$ or elements often associated with anthropogenic activities (e.g. $\mathrm{Cd}, \mathrm{Cr}, \mathrm{Ni}, \mathrm{Pb}, \mathrm{V}, \mathrm{Zn}$ ).

Depletion or enrichment of elements relative to a specific source is assessed using enrichment factors (EF) (Chester et al., 1999; Herut et al., 2001), and for marine aerosols are determined relative to crustal values:

$$
E F=\left(\frac{c_{x}^{p}}{c_{A l}^{p}}\right) /\left(\frac{c_{x}^{c}}{c_{A l}^{c}}\right)
$$

Equation 1

Where $\boldsymbol{C}_{\boldsymbol{x}}^{\boldsymbol{p}}$ and $\boldsymbol{C}_{\boldsymbol{A l}}^{\boldsymbol{p}}$ are the concentrations of the trace elements of interest and $\mathrm{Al}$ in the aerosol particulate sample, and $\boldsymbol{C}_{\boldsymbol{x}}^{\boldsymbol{c}}$ and $\boldsymbol{C}_{\boldsymbol{A} \boldsymbol{l}}^{\boldsymbol{c}}$ are the concentrations of the same two elements in crustal material. An EF value $>10$ is often taken to mean that a certain element is significantly enriched relative to typical crustal values and that a significant proportion of this element is derived from non-crustal sources.

By separating the CVAO dataset into quartiles based on total Al concentration and calculating mean crustal EF values for the upper and lower quartiles it becomes clear that the EF factors for elements with non-crustal sources vary strongly with mineral aerosol concentration (Figure 5). In the upper quartile of the CVAO dataset, the EF values for all elements were $<10$, while during less dusty periods the overall chemical composition of the aerosol load was greatly enriched in elements with non-crustal sources 
relative to UCA. These were all either major components of seawater $(\mathrm{Na}, \mathrm{Mg})$ or elements often associated with anthropogenic activities ( $\mathrm{Ag} \mathrm{Cd}, \mathrm{Cr}, \mathrm{Cu}, \mathrm{Ni}, \mathrm{Pb}, \mathrm{Sn}, \mathrm{V}$ and $\mathrm{Zn})$. Enrichment factors for these elements showed considerable variability, which agrees with findings by (Fomba et al., 2013).

\subsubsection{Excess $\mathrm{V}, \mathrm{Ni}, \mathrm{Cu}, \mathrm{Zn}, \mathrm{Pb}$}

$\mathrm{V}, \mathrm{Ni}, \mathrm{Cu}, \mathrm{Zn}$ and $\mathrm{Pb}$ are often associated with urban and industrial pollution and the burning of oil and coal; however they are also naturally present in minerals in significant quantities, with mean UCAs ranging from 20 to $71 \mathrm{\mu g} \mathrm{g}^{-1}$ (Taylor and McLennan, 1995). To allow a more detailed assessment of the non-crustal or 'excess' fractions of these elements, the crustal values were subtracted from the observed concentrations (Trapp et al., 2010). Crustal values were calculated using total Al concentrations and UCA values for the element in question (Taylor and McLennan, 1995). The excess atmospheric concentrations of $\mathrm{V}, \mathrm{Ni}, \mathrm{Cu}, \mathrm{Zn}$ and $\mathrm{Pb}$ throughout the 1 year sampling period at the CVAO are presented in Figure 6, together with total Al concentrations for comparison.

Excess $\mathrm{V}$ and $\mathrm{Ni}$ concentrations showed significant concentration maxima and a strong correlation with total $\mathrm{Al}\left(\mathrm{R}^{2}=0.89[\mathrm{~V}]\right.$ and $\left.0.75[\mathrm{Ni}]\right)$. There are no significant $\mathrm{V}$ or Ni signals in Figure 6 that do not correspond with elevated Al concentrations (except for Ni on 2 August 2007), indicating that these elements may be present in the mineral component of the aerosol samples at concentrations higher than UCA or that a secondary source of $\mathrm{Ni}$ is strongly associated, i.e. internally mixed, with mineral dust.

In the case of excess $\mathrm{Cu}$ and $\mathrm{Zn}$, there was no relationship with $\mathrm{Al}\left(\mathrm{R}^{2}=0.17\right.$ and 0.04 , respectively), despite concentration maxima all coinciding with peaks in Al, indicating possible non-crustal sources of these elements. Excess $\mathrm{Pb}$ showed a large number of concentration maxima throughout the year, with the most intense events occurring during the winter months (November to March). Although there is 
not a correlation between excess $\mathrm{Pb}$ and $\mathrm{Al}\left(\mathrm{R}^{2}=0.05\right)$, nearly all of the significant peaks in excess $\mathrm{Pb}$ coincided with a concentration maxima in total Al. This is also apparent for the concentration maxima in excess $\mathrm{Cu}$ and $\mathrm{Zn}$, suggesting that mineral dust was mixed with non-crustal particles enriched in these elements. Dust is frequently mixed with particulate pollutants in the Saharan Air Layer (Rodríguez et al., 2011). In addition to sources related to industrial and local population centres on the African continent, pollutants from Europe and North America can be rapidly transported to Africa where they are mixed with dust-laden air masses (Astitha et al., 2010; Fomba et al., 2013; Gangoiti et al., 2006; Kallos et al., 1998). Koçak et al. (2005) observed higher levels of excess Pb in dust-rich air from Africa than in air from other sectors, which they suggested may be due to Saharan dust acting as an impaction or adsorption surface for finer anthropogenic aerosols, although they could not rule out the possibility of higher anthropogenic emissions from Africa being partly or wholly responsible for the observation. Similarly, the observed coincidence of peaks in excess $\mathrm{Ni}, \mathrm{Cu}, \mathrm{Zn}$ and $\mathrm{Pb}$ with peaks in $\mathrm{Al}$ in this work is consistent with mixing and association of polluted air with mineral aerosols, although we cannot rule out the possibility that the source minerals may contain naturally higher concentrations of these elements than the mean upper crustal abundances used for the calculations.

\subsubsection{Mineralogy}

A total of 28 samples from CVAO and 7 samples from cruise D326 were analysed for mineralogy. Since small amounts of material were collected on the filters, the more heavily laden filters were generally selected for XRD analysis. An effort was made to select CVAO filters that covered a variety of dust events occurring both in winter (November - March, 22 samples) and summer (April - October, 6 samples), but with extra samples covering the cruise period (3 January - 4 February 2008, 8 samples) to compare with the 7 samples selected from cruise D326. Selected samples are indicated in the plot in 
Figure 2. This somewhat arbitrary selection of samples should not introduce bias into the conclusions, as the principal objectives of this activity were to investigate mineralogical differences between dust events originating from different source regions, and to compare the mineralogy of the CVAO and shipboard samples collected simultaneously.

Due to the low quantity of material on the filters, no extraction of the bulk or clay mineral fraction was carried out for XRD analysis and samples were run as collected. A consequence of not grinding and preparing samples using standard XRD techniques means that the mineral grains are very likely to show some preferred orientation, i.e. alignment along particular mineral faces, rather than be randomly orientated, creating systematic errors in observed diffraction intensities. This is likely to have had a significant impact on the intensities of clay peaks, for example the expandable clay fractions (illite/smectite and/or smectite) which are present in some of the filter samples, but the quantification procedure has not accounted for their occurrence. In addition, in two samples, marked preferred orientation of the quartz fraction was suspected, leading to quartz estimates in excess of $90 \%$. Such values are considered very unlikely in natural aerosol samples in the Atlantic Ocean (Weaver, 1989; Table 3) and these results have been discounted. Sodium chloride from sea spray was detected in many of the filter samples and the results were re-normalised after its removal from the data. Gypsum was identified in most of the samples, and whilst there is gypsum in the source regions it is also possible that a part of its occurrence was the result of reactions of $\mathrm{SO}_{2}$ or sulphate with calcite during atmospheric transport, as mineral dust particles are often mixed with sulphate (Dall'Osto et al., 2010; Formenti et al., 2003). Glaccum and Prospero (1980) also observed gypsum in samples collected on the Cape Verde and postulated that the gypsum had grown on the filters due to reactions between calcite and atmospheric $\mathrm{SO}_{2}$ or dissolved sea-salt sulphate. Our sampling conditions were similar to those of Glaccum and 
Prospero (1980) with a high relative humidity at the coastal sampling site, together with the presence of sulphate in marine aerosols and a relatively long ( $>24 \mathrm{~h}$ ) sampling duration which created favourable conditions for the gypsum crystals to form. Figure S1 (in appendix) indicates that gypsum levels increased with sampling duration and sampled volume of air during aerosol collection on CVAO, suggesting in situ formation. The question whether the gypsum was formed during dust transport or insitu on the filters provides uncertainty on the relative proportions gypsum and calcite in the samples, but does not affect the relative abundance of the other minerals in the collected dusts. Therefore, the possibility that some gypsum originated from arid soils cannot be excluded, but it is believed that the dominant contribution has come from reactions during transportation and/or in-situ. We therefore assumed that gypsum was a conversion product of calcite and stoichiometrically converted it to calcite.

The relative amounts of minerals in the CVAO samples are presented in order of increasing Al concentration (Figure 7). The maximum and mean of the mineral data are tabulated (Table 3), together with literature data on North African aerosols collected during dust events. Although the absolute values are not comparable, in part because of the semi-quantitative nature of our mineral analysis, there are distinct trends between the datasets. The proportion of quartz had a mean of $15 \%$, in reasonable agreement with literature values (Table 3), with typically higher contributions at higher dust loadings (Figure 7). The calcite content was up to $90.7 \%$, with a mean of $28.4 \%$, and compared with a mean of 8.2\% by Glaccum and Prospero (1980) and lower values by Avila et al. (1997) and Jeong and Achterberg (2014). The uncertainty regarding the gypsum contribution in our samples may well have contributed to the observed differences between our data and literature values. The total combined clay mineral content was up to $84.7 \%$, with a mean of $52 \%$ and highest contributions at high dust loadings; sorting the results by total atmospheric Al concentration, the combined clays represented $34 \pm 28 \%$ by mass of 
the samples in the lower quartile of the dataset, whereas in the upper quartile clays represented $66 \pm 6 \%$ of sample mass.

The most abundant clay fraction in our samples was illite (up to 53.2, mean $26.4 \%$ ), which is somewhat lower than the findings for North African dust by Glaccum and Prospero (1980) (mean 54\%) and Jeong and Achterberg (2014) (mean 72\%) at Cape Verde and Avila et al. (1997) (mean 37\%) in Spain. These workers collected their samples during dust outbreaks, which likely skewed the illite abundances to higher values (see below) relative to our data which included a mix of samples with high and low dust loadings. Under low dust loadings, pyrophyllite was observed (in four samples), with a maximum abundance of $61.7 \%$. Pyrophyllite has been reported for Silurian and Devonian rocks of the Sahara of Algeria (Chennaux and Dunoyer de Segonzac, 1967), and our dust samples may represent material sourced from this area which corresponds to source regions 1 and 2 (Fig. 1), also indicated by backtrajectory analysis for these samples. The kaolinite content was up to $57.6 \%$ with a mean of $18.7 \%$, with lowest percentages observed under low dust loadings. Our findings were higher than those by the other workers (Table 3), which may be due to their focus on dust events with lower kaolinite abundances. The chlorite abundance was relatively low (up to $23.3 \%$, mean: $6.9 \%$ ), which is higher than findings by Glaccum and Prospero (1980) (mean of 4.3\%) and (Jeong and Achterberg, 2014) (mean 3\%). Smectite, possibly including interstratified illite/smectite, was evident in some of the XRD analyses, but there was no clear source region distinction.

Quartz tends to dominate among the larger particle sizes present at high aerosol loadings (Kandler et al., 2009; Shi et al., 2005), reflecting the higher durability of quartz grains to mechanical abrasion relative to other minerals. Individual clay mineral grains typically feature submicron sizes, but these individual submicron grains are hardly deflated in the source regions because of their strong tendency 
for agglomeration. Clay minerals in the atmosphere therefore typically occur as larger agglomerates (Jeong et al., 2014). Nevertheless, at lower aerosol concentrations, where insufficient energy is available to transport the larger particles, a greater proportion of less durable minerals such as clays is present (Kandler et al., 2009). Glaccum and Prospero (1980) investigated the mineral composition of material collected during dust outbreaks at the Cape Verde, Barbados and Miami in 1974, and observed small but significant differences between average mineral composition at Cape Verde and that at Barbados and Miami, with higher mean percentages of quartz and lower mica-illite at the Cape Verde (20\% quartz content) compared with the western Atlantic sites ( $14 \%$ quartz content). The changes in mineralogy were related to the larger quartz particles (often $>50 \mu \mathrm{m}$ on Cape Verde) having a higher settling velocity in the dust plumes relative to the mica-illite (0.1-0.4 $\mu \mathrm{m})$ (Glaccum and Prospero, 1980). Our data sets obtained at the CVAO and cruise D326 showed no strong differences in mineralogical composition or in chemical composition (as discussed in Section 3.1.2), as they were collected at a distance of just a few hundred kilometres.

Leaching experiments have demonstrated that aerosol Fe solubility is highly dependent on the chemical form and reactivity of Fe in each sample and, in particular that Fe is significantly more labile in clay minerals than in more refractory phases such as quartz which has a low Fe content of typically only a few $\mu g g^{-1}$ (Götze et al., 2004) compared to 3-4 \% for illite clays (Jeong and Achterberg, 2014; Journet et al., 2008; Schroth et al., 2009). The octahedral sites of clays in the crystal structures of clay minerals can accommodate a significant quantity of Fe. As such, when estimating aerosol inputs of soluble Fe to the oceans, it is necessary to consider the mineral composition of dust.

Our data indicates pronounced variations in dust concentration with relatively small variations in mineralogy. In this study, mean total clay content in the 33 samples selected for mineralogical analysis 
varied from 34 to $66 \%$ between the lower and upper quartiles of the dataset (sorted by total atmospheric Al concentration), an increase by a factor of approximately two. This compares with the mean atmospheric Al concentration of 1.2 and $32.8 \mu \mathrm{g} / \mathrm{m}^{3}$ in the same groups; a 27 -fold increase. Considering total atmospheric Al concentrations in the dataset as a whole, there is a much greater range of values: mean values for the lower and upper quartiles of the Al-sorted dataset are $0.17 \mu \mathrm{g} / \mathrm{m}^{3}$ and $26.0 \mathrm{\mu g} / \mathrm{m}^{3}$, respectively, corresponding to a 153-fold difference. Furthermore, Glacuum and Prospero (1980) reported differences in illite content of only $10 \%$ between samples collected on either side of the Atlantic (54\% Cape Verde and 64\% Barbados) and a recent compilation of elemental ratios by (Shelley et al.), 2015) reveals only minor differences in major elemental composition of samples collected close to the African and American continents. The soluble elemental fluxes delivered to the ocean surface are therefore a strong function of the absolute dust concentration, but the intrinsic particle solubility will ultimately be determined by processes including clay content and cloud processing during transport (Baker and Croot, 2010).

\subsection{Composition in relation to source regions}

In order to further investigate aerosol sources, each sample was assigned to a source category based upon the region(s) crossed by the back trajectories. Air-masses crossing the African continent were subdivided into the three regions according to Figure 1 (Chiapello et al., 1997). Where different source regions were indicated for different arrival heights, all source regions crossed were included in the sample category.

Back trajectories for the majority of samples (122 of 154 samples from the CVAO and 9 of 29 samples collected at sea) suggested air-masses crossing more than one of the north African regions, while purely marine sources were indicated for 7 out of 29 samples from the research cruise. On one 
occasion, air-mass back trajectories indicated contributions from the North American continent in the air-masses reaching the ship.

\subsubsection{Seasonal changes at CVAO}

Meteorological conditions can change relatively rapidly, resulting in sharp changes in the source region(s) of atmospheric particles arriving at the sampling location over the course of a few hours. Since in most cases the samples were collected over a period of 2-3 days, a large proportion of the samples contained contributions from more than one source region as described in Fig. 1, which presents a challenge when investigating the characteristics of specific source regions. To establish clear differences within the CVAO dataset, a comparison was made between the climatologically distinct summer and winter periods at Cape Verde.

Samples obtained during periods with significant dust concentrations (Al equivalent to $>1 \mu \mathrm{g} \cdot \mathrm{m}^{-3}$ TSP) between July 2007 and July 2008 were separated into summer and winter periods. These periods were selected based on a marked changes in aerosol Al concentration occurring in early November 2007 and late March 2008 and differ slightly from the October and March seasonal boundaries chosen by Chiapello $(1997 ; 1995)$.

During the summer months, our data showed that $92.5 \%$ of samples contained a contribution from the Sahel (Region 1). This is in line with previous reports, since dust from the Sahel and southern Sahara is transported to the Atlantic Ocean via the SAL, which occurs predominantly in summer (Prospero and Lamb, 2003). During winter, there is a marked decrease in samples containing contributions from Region 1 (52.3\% of samples), as Regions 2 (South and Central Sahara) and 3 (North and West Sahara) become 
more important due to dust transport to the Cape Verde being controlled by the north-easterly trade winds.

\subsubsection{Elemental ratios}

Elemental ratios (nss $\mathrm{Mg} / \mathrm{Al}$, nss $\mathrm{K} / \mathrm{Al}$, nss $\mathrm{Ca} / \mathrm{Al}$, Fe/nss $\mathrm{Ca}$ and nss $\mathrm{K} / \mathrm{nss} \mathrm{Ca}$; nss means non sea salt) were used as geochemical signatures to establish aerosol source regions. These ratios have previously been found to act as useful finger prints of source region (Chiapello et al., 1997; Gelado-Caballero et al., 2012; Guieu et al., 2002; Lafon et al., 2006; Moreno et al., 2006). Additionally, the elemental ratios of $\mathrm{V} / \mathrm{Al}, \mathrm{Ni} / \mathrm{Al}, \mathrm{Cu} / \mathrm{Al}, \mathrm{Zn} / \mathrm{Al}, \mathrm{Cd} / \mathrm{Al}$ and $\mathrm{Pb} / \mathrm{Al}$ were investigated to determine the relative contributions of anthropogenic elements from different source regions to the aerosol samples. As far as possible, samples were selected with back trajectories indicating one of the three Chiapello source regions. Due to a lack of samples exclusively from Region 3, samples from Region 1 (Sahel), Region 2 (South / Central Sahara) and Regions $2+3$ (S/C Sahara + NW Sahara) were compared.

Table 4 shows the mean ratios for each of the regions, together with the number of measurements, and their standard deviations. The values for the three regions were close and with relatively large standard deviations, particularly for Region 1 (Sahel). Significant differences $(p<0.05)$ were found between Regions 1 (Sahel) and 2 (South / Central Sahara) for nss Mg/Al ( $p=0.034)$ and nss K/Al ( $p=$ 0.042). Between Regions 1 (Sahel) and 2+3 (NW \& South / Central Sahara) there were significant differences for $\mathrm{nss} \mathrm{Mg/AI}(p=0.016)$ and nss K/Ca $(p=0.043)$. Hence the only clear difference between Sahel and Saharan samples is in the nss $\mathrm{Mg} / \mathrm{Al}$ ratio, with significantly higher values in samples originating from the Sahel $(0.30 \pm 0.19)$ than in the South / Central Sahara $(0.17 \pm 0.05)$ or NW \& South / Central Sahara combined $(0.16 \pm 0.04)$. This is the opposite trend to previous observations of higher $\mathrm{Mg} / \mathrm{Al}$ ratios towards the north and lower values in the Sahel (for a summary of previous observations, 
see Gelado-Caballero et al., 2012). Our 2-3 days sampling duration may have resulted in collection of aerosols from multiple source regions, removing distinct geochemical signatures in other elements that have been observed by others (Chiapello et al., 1997). Furthermore, the coastal location of the CVAO further complicated our analysis due to the presence of significant quantities of sea salt in the samples. Large corrections were applied to $\mathrm{Mg}$, $\mathrm{K}$ and Ca values (50\%, $19 \%$ and $12 \%$ average correction, respectively) to remove the marine component and this may be the source of a significant proportion of the variability in ratios involving these elements.

A summary of a similar analysis for the anthropogenic elemental ratios (V/Al, Ni/Al, $\mathrm{Cu} / \mathrm{Al}, \mathrm{Zn} / \mathrm{Al}$, $\mathrm{Cd} / \mathrm{Al}$ and $\mathrm{Pb} / \mathrm{Al}$ ) is shown in Table 5. In contrast to the ratios involving crustal / marine components, clear differences are apparent between Region 1 (Sahel) and Regions 2 and 3 (South / Central Sahara and NW Sahara), with higher values for all ratios found in samples with more southern origins. Statistically significant differences between samples originating from Region 1 (Sahel) and from Region 2 (South / Central Sahara) were found only for Cd/Al $(p<0.004)$ and $\mathrm{Pb} / \mathrm{Al}(\mathrm{p}=0.002)$ ratios, while a comparison of samples originating from Region 1 (Sahel) with those indicating Regions 2 \& 3 (South / Central Sahara and NW Sahara) show significant $(p<0.01)$ differences for all 6 elemental ratios listed in Table 5. Differences are greatest for $\mathrm{Cd}$ and $\mathrm{Zn}$, which show ratios with $\mathrm{Al}$ approximately 4 times greater in the Sahel. Guieu et al. (2002) reported Pb/Al ratios for Saharan dust samples collected in Corsica of $0.00069 \pm 0.00022$, which are comparable with our value of $0.0013 \pm 0.0014$ for Regions $2 \& 3$ (South / Central Sahara and NW Sahara). Our higher values of anthropogenic elements for the Sahel (Region 1) are likely due to the higher population density in this region, resulting in higher anthropogenic emissions, compared with the more remote desert areas to the north. This contrasts with findings by 
Rodriguez (2011), which identified greater anthropogenic contributions from more northern sources. However this study was conducted further north at the Canary Islands.

\subsubsection{Rare Earth Element patterns}

Rare earth elements (REE) are relatively immobile in sediments and are subjected to little fractionation during chemical and physical weathering (Muhs et al., 2007). Therefore, REE patterns in sediments represent a signature of igneous processes that occurred during the formation of the parent rock and can be used as indicators of the provenance of sedimentary materials (Muhs et al., 2007). The REE patterns were calculated for the data from the CVAO to facilitate differentiation between aerosol source regions. Absolute REE concentrations $\left(\mu \mathrm{g} \cdot \mathrm{kg}^{-1}\right.$ - calculated using total Al concentrations and assuming $8.04 \% \mathrm{w} / \mathrm{w} \mathrm{Al}$ ) were normalised to chondritic meteorite compositions (taken from Taylor and Gorton, 1977) according to Equation 2, where the chondrite normalised REE concentration for a given REE element in a sample is given by $x_{N}^{R E E}, x_{a b s}^{R E E}$ and $x_{a b s}^{A l}$ refer to the absolute amounts of the REE and $\mathrm{Al}$ measured in the sample, and $x_{\text {chon }}^{R E E}$ is the chondritic meteorite composition as given by Taylor and Gorton (1977).

$x_{N}^{R E E}=\frac{x_{a b s}^{R E E}}{x_{a b s}^{A l}} \times \frac{10^{9}}{x_{c h o n}^{R E E}} \times \frac{8.04}{100}$ Equation 2

Figure 8 presents REE patterns plotted using mean values for samples from five different source region categories according to air-mass back-trajectories. A very similar REE pattern was obtained for samples from all regions, with light rare earth elements (LREE) significantly enriched relative to the heavy rare earth elements (HREE), a relatively flat and uniform HREE pattern and a marked depletion in Eu relative to its neighbouring elements, $\mathrm{Sm}$ and $\mathrm{Gd}$. This pattern is typical of sedimentary materials 
derived from post-Archean continental crust and is found in sediments from around the world with remarkable uniformity (Taylor and McLennan, 1995). Profiles typically differ the most in the level of HREE enrichment and the degree of Eu depletion relative to the other REEs (termed a negative Eu anomaly - formed during magma crystallisation into stable plagioclase with preferential Eu incorporation into this mineral and consequent depletion of Eu in the rest of the magma). A visual inspection of the CVAO data in Figure 8 shows that there is more variation in these two parts of the REE pattern.

To facilitate the comparison of REE data for source identification three parameters were calculated: the Europium anomaly, $\mathrm{Eu}_{N} / \mathrm{Eu}^{*}$, where $\mathrm{Eu}_{\mathrm{N}}$ is the Chondrite normalised Eu concentration and $\mathrm{Eu}^{*}$ is the "expected" Europium concentration based on interpolation between Chondrite normalised Sm and Gd concentrations $\left(\mathrm{Eu}^{*}=\left(\mathrm{Sm}_{\mathrm{N}} \times \mathrm{Gd}_{\mathrm{N}}\right)^{1 / 2}\right) . \mathrm{Eu}_{\mathrm{N}} / \mathrm{Eu}^{*}$ is $<1$ for a negative Europium anomaly (Eu depleted relative to its neighbouring REEs) and $>1$ for a positive anomaly. $\mathrm{La}_{N} / \mathrm{Yb}_{\mathrm{N}}$, a measure of the $\mathrm{LREE}$ enrichment relative to HREE, is calculated from the ratio of the Chondrite normalised values for La and $\mathrm{Yb}$, with higher values indicating more LREE enrichment. $G d_{N} / Y_{N}$ is a measure of HREE depletion, with higher values indicating more depletion of the heavier elements relative to $\mathrm{Gd}$. Uncertainties in the calculated REE metrics were determined from the measurements of 23 independent digestions of the loess sediment that was used as a reference material. The standard deviations of these measurements were $0.014\left(\mathrm{Eu}_{\mathrm{N}} / \mathrm{Eu}^{*}\right), 0.12\left(\mathrm{La}_{N} / \mathrm{Yb}_{\mathrm{N}}\right)$, and $0.078\left(\mathrm{Gd}_{N} / \mathrm{Yb}_{\mathrm{N}}\right)$.

All of the CVAO data fell within, or were very close to literature values for African dust of $\mathrm{Eu}_{\mathrm{N}} / \mathrm{Eu}^{*} \sim$ $0.55-0.80 ; \mathrm{La}_{N} / \mathrm{Yb}_{\mathrm{N}} \sim 5-12.5$, and $\mathrm{Gd} \mathrm{d}_{N} / \mathrm{Yb}_{\mathrm{N}} \sim 1-2.5$ (Muhs et al., 2007). $\mathrm{Gd}_{N} / \mathrm{Yb}_{\mathrm{N}}$ values for all five source regions span a very similar range and have similar mean values, suggesting that there is little difference in the HREE values between the different source regions (Figure 9a). $\mathrm{La}_{N} / \mathrm{Yb}_{\mathrm{N}}$ and $\mathrm{Eu} \mathrm{u}_{\mathrm{N}} / \mathrm{Eu}^{*}$ 
values showed some differences between the different regions, although there was a large amount of overlap between the values for different regions (Figure 9b). Despite the scatter a general trend can be observed (Figure 9b), with samples from Region 1 (Sahel) tending towards higher $L a_{N} / Y_{N}$ and lower $\mathrm{Eu}_{\mathrm{N}} / \mathrm{Eu}^{*}$, Regions $2+3$ (Sahara) tending towards lower $\mathrm{La}_{\mathrm{N}} / \mathrm{Yb}_{\mathrm{N}}$ and higher $\mathrm{Eu}_{\mathrm{N}} / \mathrm{Eu}^{*}$ and Regions 2 (and samples with a mixture of Regions 1, 2 and 3) coming somewhere in between. $\mathrm{Eu}_{N} / \mathrm{Eu}^{*}$ appeared to be a better indicator of source than $\mathrm{La}_{\mathrm{N}} / \mathrm{Yb}_{\mathrm{N}}$, with most samples from Regions 1 and from Regions $1+2+3$ showing $\mathrm{Eu}_{\mathrm{N}} / \mathrm{Eu}^{*}<0.7$, and most samples from Regions 2 and $2+3$ showing $\mathrm{Eu}_{\mathrm{N}} / \mathrm{Eu}^{*}>0.7$. However, these patterns were too weak to be used as an accurate indicator of aerosol source. Our CVAO observations are consistent with the findings of Moreno et al. (2006), who conducted a geochemical study of dust samples collected in various locations across the Sahel and Sahara and found only relatively small variations in REE concentrations.

Figure $9 c$, d show the REE Eu anomalies plotted against $G d_{N} / Y_{N}$ and $L a_{N} / Y b_{N}$, respectively, for samples collected during the research cruise. In agreement with the corresponding data for the CVAO data, samples from Region 1 again showed a low Eu anomaly $(<0.68)$, with the two samples containing a contribution from Region 3 showing higher Eu anomalies $(0.70-0.76)$. However the small number of samples and the high degree of scatter precludes any meaningful analysis of the distribution in terms of source region. Despite this, a wide distribution of Eu anomalies were measured in the shipboard samples, and when plotted in a chronological order (Figure 10a) revealed a clear distinction in $\mathrm{Eu}_{\mathrm{N}} / \mathrm{Eu}^{*}$ ratios between the first dust event (16-20 January 2008) and the subsequent two events (25-27 January 2008 and $28-31$ January 2008).

During the first dust event (16-20 January 2008) Eu anomalies were in the range $0.71-0.76$. Air mass back-trajectories corresponding to this period indicated a mixture of Regions 1 and 2 as the source 
of the dust for this period. In the second event (25-27 January 2008) Eu anomalies were significantly lower: $0.66-0.68(p<0.001)$ and the back-trajectory analysis indicated Region 2 as the dominant source region, shifting to Region 1 towards the end of the period. The third event (28-31 January 2008) was characterised by intermediate Eu anomalies (0.68-0.71), and during this period the South and Central Sahara (Region 2) formed the dominant aerosol source region.

Figure 10b shows Eu anomalies for the CVAO obtained during the same period as cruise D326, with two dust events arriving at CVAO with peak concentrations on 21 January and 29 January 2008 and corresponding with the first and second/third dust event encountered on D326. A similar reduction in the $\mathrm{Eu}_{\mathrm{N}} / \mathrm{Eu} *$ ratios was noticeable in the CVAO dataset, however the source regions differed. At the CVAO, the first event (peaking 21 January 2008) had back trajectories originating in Regions 2 and 3, whereas the later event (29 January 2008) originated from a mixture of Regions 1 and 2. This lack of correspondence between the air-mass back trajectories despite the REE signatures suggesting a similar shift in source region may be due to the difficulties of accurately classifying air-mass back trajectories for samples collected over longer periods. However, these results demonstrate the ability of REE ratio measurements to distinguish dust from different sources, particularly when shorter ( $<24$ hour) sampling periods are used such that atmospheric conditions do not change significantly during the collection of an individual sample.

\subsubsection{Clay mineralogy as source fingerprints}

Separation of the XRD samples according to air mass classification allows a more informed analysis of the mineral data. Source area 2, i.e. the South and Central Saharan region was characterized by a positive statistical correlation between \%kaolinite, \%quartz and Al concentration $\left(r^{2}=0.92, n=5\right.$; and $r^{2}=0.56, n=6$ respectively). The relationship with illite/kaolinite ratio was negative $\left(r^{2}=-0.34, n=5\right)$ and as 
might be expected calcite had a negative correlation $\left(r^{2}=0.55, n=6\right)$ with Al content. By comparison, samples originating from a mix of sources 1 (Sahel region) and 2, exhibited a positive relationship between $\mathrm{Al}$ and the quartz/calcite ratio $\left(r^{2}=0.83, n=10\right)$ only. The negligible correlation between \%kaolinite and this sample grouping $\left(r^{2}=0.01, n=8\right)$ inferred that the 'quartz' and 'Al' signal from Source 1 dominated, over that for Source 2 to the north. Samples designated as from sources 2 and 3 (North and West Sahara) had a positive correlation between Al and the quartz/calcite ratio $\left(r^{2}=0.91, n=5\right)$ and also with illite $\left(r^{2}=0.84, n=5\right)$. Although, Al content was negatively correlated with $\%$ kaolinite $\left(r^{2}=-0.27\right.$, $\mathrm{n}=5$ ). During the dust events it seems reasonable to infer that Source 3 dominated over Source 2, given the importance of illite and the relative unimportance of kaolinite. Finally, several samples were likely to comprise a mix of aeolian sources 1, 2 and 3, in which positive correlations were seen between $\mathrm{Al}$ and both the quartz/ kaolinite ratio $\left(r^{2}=0.92, n=5\right)$ and the quartz/calcite ratio $\left(r^{2}=0.98, n=5\right)$. Again the subsidiary role of the South and central Saharan region (Source 2) was inferred by the reduction of kaolinite in the presence of Al.

Aeolian dust from the South and Central Saharan region (Source 2) appeared unique in terms of its kaolinite signal and reduction in illite with increasing Al, although the significance of this source in terms of quantity was likely to be low, when compared to regions both to the north and south. Also illite appeared to be preferentially sourced from the North and West Sahara, in agreement with findings by others (Caquineau et al., 1998). All regions showed a reduction in calcite content and an increase in quartz with increased Al content.

Illite / kaolinite clay ratios are thus a useful indicator of African source regions (Caquineau et al., 2002; Caquineau et al., 1998), due to much greater abundance of kaolinite in the Sahel and southern Sahara than in the regions further north. Possibly due to the mixed nature of many of the CVAO 
samples, there is considerable scatter in the Illite / kaolinite ratios. However when plotted against Eu/Eu*, a separation was obtained between the groups of samples (Figure 11). Samples including contributions from the Sahel (Region 1) showed lower Illite / kaolinite and Eu/Eu* ratios, while samples originating exclusively from the Sahara (Regions 2 and 3) displayed higher Illite / kaolinite and Eu/Eu* values (with the exception of one point). These observations are comparable to other studies (Goudie and Middleton, 2006). Therefore the combined use of mineral and elemental tracers can aid in the unravelling of source regions of dust samples.

\section{Conclusions}

During the course of a one year period at the CVAO numerous dust events of varying intensities were observed and the seasonal changes in aerosol concentration were noticeable with higher levels in winter compared with summer periods. A clear shift in aerosol back-trajectories was seen, with dust sources from the Sahel region more important during the summer, being replaced by more northern sources during the winter period when north-easterly trade winds dominate dust transport to the region. Despite this there was a high level of consistency in the chemical composition of the collected dust samples, with many of the 42 elements displaying a strong correlation to Al. A unique opportunity to sample simultaneously on land and at sea was obtained during January 2008 during which mean mineral dust concentrations were estimated at up to $215 \mu \mathrm{g} \mathrm{m}^{-3}$. Although measured dust concentrations differed significantly between the two sets of measurements, both sets of samples showed considerable chemical and mineralogical similarity, with REE patterns indicating the same trends. 
Overall, trends in REE patterns were noticeable when comparing samples from climatologically different periods, particularly in the shipboard samples, but the longer sampling periods (1-3 days) used for the samples from CVAO resulted in most of these containing a contribution from a mixture of source regions. Nevertheless, combined with illite/kaolinite ratios from XRD analysis, differences can be observed between aerosols from the Sahel and from the more northern Sahara region.

Enrichment factors suggest that elements typically associated with anthropogenic activity $(\mathrm{Ag}, \mathrm{Cd}$, $\mathrm{Cr}, \mathrm{Cu}, \mathrm{Ni}, \mathrm{Pb}, \mathrm{Sn}, \mathrm{V}, \mathrm{Zn}$ ) were enriched relative to their crustal abundance at low aerosol concentrations. However, all of these elements showed positive correlations with Al, and their concentrations were highest during dust events. $\mathrm{V}, \mathrm{Ni}$ and $\mathrm{Pb}$ showed most pronounced anthropogenic contributions, yet showed a strong association with mineral dust that is possibly the result of mixing of anthropogenically derived aerosols with mineral dust during transport. An analysis of anthropogenic elemental ratios according to aerosol source region revealed significantly higher levels of these elements in samples from the Sahel. Cd/Al and Zn/Al were particularly elevated in samples originating from this region, with levels 4 times greater than in samples indicating source regions in the less populated Sahara regions further north.

Mineral analysis showed an important presence of quartz, with a slightly higher abundance during periods of high dust concentration. However, clay minerals, in particular illite, were the most abundant minerals in almost all samples, showing a marked increase at elevated dust concentrations. This has important implications for the estimation of the release of biogeochemically important species such as Fe from mineral dust due to the higher Fe solubility of clays. Nevertheless, the observed variations in mineral composition were relatively minor in comparison with variations in absolute aerosol 
concentrations at CVAO. This highlights the importance of continuous high resolution measurements of aerosol concentrations in conjunction with studies of aerosol composition.

\section{Acknowledgements}

We thank all the staff involved with the CVAO (including Luis Mendes, Lucy Carpenter and Katie Read) for their excellent support in enabling the aerosol sampling. We express our gratitude to the Master and crew of RRS Discovery for their support and to thank Mark Stinchcombe for handling the logistics of the cruise. We gratefully acknowledge Ross Williams for his assistance with the XRD analysis, Dr Matthew Cooper for his help with the optimization of the sample digestion method and Dr Andy Milton for facilitating the ICP-MS analyses. Finally, we would like to thank Dr Zongbo Shi, Dr Gi Yong Jeong, Dr Gelado Caballero and two anonymous reviewers for their helpful and constructive comments on earlier drafts of the manuscript. This research was funded by NERC as part of the UK SOLAS programme, project grant number NE/C001931/1, and we acknowledge German SOPRAN project for funding the final write-up of the manuscript (BMBF project 03F0662A). 


\section{Tables}

Table 1. Average instrumental blank concentrations (dilute $\mathrm{HNO}_{3} ; \mathrm{n}=13$ measurements), average filter blanks for total acid digestions $(n=18)$, and mean \% recovery ( \pm 1 standard deviation) from Certified Reference Materials (CRMs) in total acid digestions. All blank values have been converted into atmospheric units ng. $\mathrm{m}^{-3}$, using filter digestion volume of ca. $20 \mathrm{~mL}$ and assumed sample air volume of $100 \mathrm{~m}^{3}$.

\begin{tabular}{|c|c|c|c|c|}
\hline Element & $\begin{array}{l}\text { Instrumental } \\
\text { Blank Mean }\end{array}$ & $\begin{array}{l}\text { Digestion Blank } \\
\text { Mean }\end{array}$ & LOESS CRM \% recovery & NIST1648a \% recovery \\
\hline $\mathrm{Na}$ & $<0.097$ & 10 & $109 \% \pm 8 \%$ & $108 \% \pm 7 \%$ \\
\hline$M g$ & 0.13 & 2.2 & $109 \% \pm 8 \%$ & $102 \% \pm 6 \%$ \\
\hline $\mathrm{Al}$ & $<0.052$ & 4.6 & $107 \% \pm 9 \%$ & $105 \% \pm 7 \%$ \\
\hline K & 0.37 & 3.5 & & \\
\hline $\mathrm{Ca}$ & $<0.42$ & 9.7 & $110 \% \pm 8 \%$ & $106 \% \pm 7 \%$ \\
\hline Sc & $<0.0016$ & 0.0029 & & \\
\hline $\mathrm{Ti}$ & $<0.038$ & 1.5 & $103 \% \pm 11 \%$ & $100 \% \pm 9 \%$ \\
\hline V & $<0.0022$ & 0.039 & $101 \% \pm 13 \%$ & $104 \% \pm 13 \%$ \\
\hline $\mathrm{Cr}$ & $<0.0024$ & 0.94 & $101 \% \pm 12 \%$ & $96 \% \pm 11 \%$ \\
\hline $\mathrm{Mn}$ & $<0.0021$ & 0.019 & $105 \% \pm 8 \%$ & $101 \% \pm 6 \%$ \\
\hline $\mathrm{Fe}$ & $<0.035$ & 1.4 & $107 \% \pm 11 \%$ & $105 \% \pm 11 \%$ \\
\hline Co & $<0.00038$ & 0.0012 & $103 \% \pm 11 \%$ & $101 \% \pm 13 \%$ \\
\hline $\mathrm{Ni}$ & $<0.0022$ & 0.089 & $96 \% \pm 11 \%$ & $89 \% \pm 10 \%$ \\
\hline $\mathrm{Cu}$ & $<0.0050$ & 0.041 & $96 \% \pm 9 \%$ & $87 \% \pm 7 \%$ \\
\hline $\mathrm{Zn}$ & $<0.022$ & 0.84 & $97 \% \pm 9 \%$ & $82 \% \pm 9 \%$ \\
\hline Ga & $<0.00067$ & 0.0014 & & \\
\hline $\mathrm{Rb}$ & $<0.0011$ & 0.0051 & $101 \% \pm 9 \%$ & $88 \% \pm 9 \%$ \\
\hline $\mathrm{Sr}$ & $<0.00096$ & 0.064 & $103 \% \pm 8 \%$ & $96 \% \pm 9 \%$ \\
\hline Y & $<0.000096$ & 0.11 & $85 \% \pm 8 \%$ & \\
\hline $\mathrm{Nb}$ & $<0.00036$ & 0.0087 & & \\
\hline $\mathrm{Ag}$ & $<0.00033$ & 0.0040 & & \\
\hline $\mathrm{Cd}$ & $<0.00024$ & 0.0012 & & \\
\hline Sn & $<0.00091$ & 0.17 & & \\
\hline Cs & $<0.000078$ & 0.00052 & $101 \% \pm 4 \%$ & $93 \% \pm 3 \%$ \\
\hline $\mathrm{Ba}$ & $<0.0026$ & 0.033 & & \\
\hline La & $<0.000086$ & 0.0015 & $105 \% \pm 12 \%$ & $93 \% \pm 4 \%$ \\
\hline $\mathrm{Ce}$ & $<0.00017$ & 0.005 & $105 \% \pm 12 \%$ & $95 \% \pm 4 \%$ \\
\hline $\operatorname{Pr}$ & $<0.000040$ & 0.00033 & $107 \% \pm 13 \%$ & \\
\hline $\mathrm{Nd}$ & $<0.00023$ & 0.0012 & $105 \% \pm 13 \%$ & \\
\hline Sm & $<0.00012$ & $<0.00012$ & $104 \% \pm 12 \%$ & $89 \% \pm 4 \%$ \\
\hline
\end{tabular}




\begin{tabular}{|c|c|c|c|c|}
\hline $\mathrm{Eu}$ & $<0.000032$ & $<0.000032$ & $101 \% \pm 8 \%$ & \\
\hline $\mathrm{Gd}$ & $<0.000051$ & 0.00026 & $115 \% \pm 11 \%$ & \\
\hline $\mathrm{Tb}$ & $<0.000015$ & $<0.000015$ & $97 \% \pm 8 \%$ & \\
\hline Dy & $<0.000023$ & 0.00019 & $86 \% \pm 7 \%$ & \\
\hline Ho & $<0.0000074$ & 0.000013 & $81 \% \pm 7 \%$ & \\
\hline $\mathrm{Er}$ & $<0.000016$ & 0.000066 & $79 \% \pm 6 \%$ & \\
\hline $\mathrm{Tm}$ & $<0.0000046$ & $<0.0000046$ & $81 \% \pm 6 \%$ & \\
\hline $\mathrm{Yb}$ & $<0.000014$ & 0.000078 & $75 \% \pm 6 \%$ & \\
\hline Lu & $<0.0000042$ & $<0.0000042$ & $74 \% \pm 6 \%$ & \\
\hline $\mathrm{Pb}$ & $<0.00024$ & 0.022 & $110 \% \pm 11 \%$ & $102 \% \pm 5 \%$ \\
\hline Th & $<0.000030$ & 0.00044 & $100 \% \pm 19 \%$ & \\
\hline U & $<0.000019$ & 0.00018 & $91 \% \pm 14 \%$ & \\
\hline
\end{tabular}


Table 2. Atmospheric concentrations of trace elements in aerosols sampled at the CVAO from 2 July 2007 to 11 July 2008 and during a research cruise D326 aboard RRS Discovery from 8 January to 4 February 2008. Values less than the blank are indicated by n.d.; Ga was not measured for the samples from D326.

\begin{tabular}{|c|c|c|c|c|c|c|c|c|c|c|c|}
\hline \multirow{2}{*}{\multicolumn{2}{|c|}{ Element }} & \multirow{3}{*}{$\begin{array}{l}\text { Min } \\
0.61\end{array}$} & \multicolumn{3}{|c|}{ CVAO July 2007 - July 2008} & \multirow[b]{2}{*}{$\begin{array}{l}\text { Standard } \\
\text { deviation }\end{array}$} & \multicolumn{5}{|c|}{ RRS Discovery (D326) - January 2008} \\
\hline & & & Max & $\begin{array}{l}\text { Arithmetic } \\
\text { mean }\end{array}$ & $\begin{array}{c}\text { Geometric } \\
\text { mean }\end{array}$ & & \multirow{2}{*}{$\begin{array}{l}\text { Min } \\
\text { n.d. }\end{array}$} & \multirow{2}{*}{$\begin{array}{l}\text { Max } \\
11.7\end{array}$} & \multirow{2}{*}{$\begin{array}{c}\text { Arithmetic } \\
\text { mean }\end{array}$} & \multirow{2}{*}{$\begin{array}{c}\begin{array}{c}\text { Geometric } \\
\text { mean }\end{array} \\
4.82\end{array}$} & \multirow{2}{*}{$\begin{array}{c}\begin{array}{c}\text { Standard } \\
\text { deviation }\end{array} \\
2.67\end{array}$} \\
\hline $\mathrm{Na}$ & $\left(\mu \mathrm{g} \cdot \mathrm{m}^{-3}\right)$ & & 12.3 & 3.93 & 3.51 & 1.90 & & & & & \\
\hline Mg & $\left(\mu \mathrm{g} \cdot \mathrm{m}^{-3}\right)$ & 0.11 & 9.57 & 0.99 & 0.76 & 1.03 & n.d. & 5.16 & 2.13 & 1.47 & 1.58 \\
\hline Al & $\left(\mu \mathrm{g} \cdot \mathrm{m}^{-3}\right)$ & 0.01 & 66.9 & 2.89 & 0.76 & 6.99 & n.d. & 36.2 & 10.5 & 2.24 & 11.3 \\
\hline K & $\left(\mu \mathrm{g} \cdot \mathrm{m}^{-3}\right)$ & 0.04 & 10.7 & 0.77 & 0.36 & 1.37 & 0.001 & 6.06 & 1.99 & 0.81 & 1.91 \\
\hline $\mathrm{Ca}$ & $\left(\mu \mathrm{g} \cdot \mathrm{m}^{-3}\right)$ & 0.06 & 15.3 & 1.38 & 0.74 & 1.99 & n.d. & 9.22 & 3.27 & 1.56 & 3.08 \\
\hline Sc & (ng.m ${ }^{-3}$ ) & 0.003 & 11.6 & 0.54 & 0.16 & 1.24 & 0.01 & 6.37 & 1.86 & 0.47 & 1.99 \\
\hline $\mathrm{Ti}$ & $\left(\mu \mathrm{g} \cdot \mathrm{m}^{-3}\right)$ & 0.0001 & 3.78 & 0.16 & 0.04 & 0.40 & n.d. & 1.95 & 0.60 & 0.13 & 0.62 \\
\hline V & (ng. $\left.\mathrm{m}^{-3}\right)$ & 0.12 & 80.7 & 5.33 & 2.82 & 8.78 & n.d. & 41.4 & 13.9 & 4.94 & 13.4 \\
\hline $\mathrm{Cr}$ & (ng.m ${ }^{-3}$ ) & 0.39 & 64.0 & 4.09 & 2.42 & 6.75 & n.d. & 34.8 & 11.2 & 5.18 & 10.9 \\
\hline Mn & (ng.m ${ }^{-3}$ ) & 0.12 & 606 & 25.8 & 7.11 & 63.5 & n.d. & 307 & 93.3 & 22.3 & 98.2 \\
\hline $\mathrm{Fe}$ & $\left(\mu \mathrm{g} \cdot \mathrm{m}^{-3}\right)$ & 0.01 & 33.4 & 1.58 & 0.45 & 3.61 & n.d. & 18.5 & 5.38 & 1.25 & 5.72 \\
\hline Co & (ng. $\left.\mathrm{m}^{-3}\right)$ & 0.01 & 14.5 & 0.69 & 0.22 & 1.56 & n.d. & 7.98 & 2.41 & 0.64 & 2.53 \\
\hline $\mathbf{N i}$ & (ng.m ${ }^{-3}$ ) & 0.04 & 29.3 & 2.06 & 1.22 & 3.03 & n.d. & 15.6 & 5.06 & 2.13 & 4.92 \\
\hline $\mathrm{Cu}$ & (ng.m $\mathrm{m}^{-3}$ ) & 0.02 & 23.6 & 1.44 & 0.65 & 2.66 & n.d. & 13.6 & 4.23 & 1.81 & 4.18 \\
\hline $\mathrm{Zn}$ & (ng.m ${ }^{-3}$ ) & 0.36 & 52.7 & 6.31 & 4.32 & 6.95 & n.d. & 61.0 & 11.1 & 6.16 & 12.3 \\
\hline Ga & (ng. $\mathrm{m}^{-3}$ ) & 0.04 & 5.43 & 1.22 & 0.74 & 1.24 & $\mathrm{n} / \mathrm{a}$ & $\mathrm{n} / \mathrm{a}$ & $\mathrm{n} / \mathrm{a}$ & $\mathrm{n} / \mathrm{a}$ & $\mathrm{n} / \mathrm{a}$ \\
\hline $\mathbf{R b}$ & (ng.m ${ }^{-3}$ ) & 0.02 & 63.8 & 2.83 & 0.86 & 6.55 & n.d. & 31.0 & 9.42 & 2.71 & 9.89 \\
\hline $\mathrm{Sr}$ & (ng.m ${ }^{-3}$ ) & 0.74 & 194 & 13.8 & 7.24 & 23.7 & n.d. & 133 & 36.7 & 17.4 & 37.4 \\
\hline$Y$ & (ng. $\mathrm{m}^{-3}$ ) & 0.01 & 25.2 & 1.48 & 0.46 & 3.20 & n.d. & 12.7 & 4.60 & 1.88 & 4.16 \\
\hline $\mathrm{Nb}$ & (ng.m ${ }^{-3}$ ) & 0.002 & 14.6 & 0.61 & 0.19 & 1.52 & n.d. & 6.57 & 2.06 & 0.89 & 2.00 \\
\hline
\end{tabular}




\begin{tabular}{|c|c|c|c|c|c|c|c|c|c|c|c|}
\hline \multirow{2}{*}{\multicolumn{2}{|c|}{ Element }} & \multicolumn{5}{|c|}{ CVAO July 2007 - July 2008} & \multicolumn{5}{|c|}{ RRS Discovery (D326) - January 2008} \\
\hline & & \multirow{2}{*}{$\begin{array}{c}\text { Min } \\
0.15\end{array}$} & \multirow{2}{*}{$\begin{array}{c}\text { Max } \\
256\end{array}$} & \multirow{2}{*}{$\begin{array}{c}\text { Arithmetic } \\
\text { mean }\end{array}$} & \multirow{2}{*}{$\begin{array}{c}\begin{array}{c}\text { Geometric } \\
\text { mean }\end{array} \\
10.0\end{array}$} & \multirow{2}{*}{$\begin{array}{c}\begin{array}{c}\text { Standard } \\
\text { deviation }\end{array} \\
33.6\end{array}$} & & \multirow{2}{*}{$\begin{array}{c}\text { Max } \\
115\end{array}$} & \multirow{2}{*}{$\begin{array}{c}\text { Arithmetic } \\
\text { mean }\end{array}$} & \multirow{2}{*}{$\begin{array}{c}\begin{array}{c}\text { Geometric } \\
\text { mean }\end{array} \\
19.1\end{array}$} & \multirow{2}{*}{$\begin{array}{c}\begin{array}{c}\text { Standarc } \\
\text { deviatior }\end{array} \\
33.6\end{array}$} \\
\hline $\mathrm{Ag}$ & $\left(\right.$ pg.m $\left.{ }^{-3}\right)$ & & & & & & n.d. & & & & \\
\hline Cd & $\left(\right.$ pg.m $\left.\mathrm{m}^{-3}\right)$ & 0.77 & 169 & 24.8 & 17.2 & 21.7 & n.d. & 165 & 40.8 & 27.7 & 35.2 \\
\hline Sn & (ng. $\left.\mathrm{m}^{-3}\right)$ & 0.001 & 3.18 & 0.30 & 0.17 & 0.42 & n.d. & 2.46 & 0.60 & 0.37 & 0.60 \\
\hline Cs & $\left(\right.$ pg. $\left.\mathrm{m}^{-3}\right)$ & 0.85 & 2935 & 147 & 47.4 & 319 & n.d. & 1514 & 480 & 149 & 502 \\
\hline $\mathrm{Ba}$ & (ng. $\mathrm{m}^{-3}$ ) & 0.03 & 434 & 21.1 & 5.43 & 48.2 & n.d. & 243 & 74.2 & 17.2 & 76.5 \\
\hline La & (ng. $\left.\mathrm{m}^{-3}\right)$ & 0.01 & 37.6 & 1.54 & 0.42 & 3.91 & n.d. & 19.4 & 5.59 & 1.21 & 6.12 \\
\hline $\mathrm{Ce}$ & (ng. $\mathrm{m}^{-3}$ ) & 0.01 & 80.3 & 3.25 & 0.83 & 8.34 & n.d. & 40.3 & 11.8 & 2.54 & 12.9 \\
\hline $\operatorname{Pr}$ & $\left(\right.$ pg.m $\left.{ }^{-3}\right)$ & 1.14 & 8307 & 362 & 94.0 & 890 & n.d. & 4642 & 1361 & 288 & 1486 \\
\hline Nd & (ng. m $^{-3}$ ) & 0.004 & 34.6 & 1.38 & 0.35 & 3.53 & n.d. & 17.5 & 5.15 & 1.08 & 5.61 \\
\hline Sm & $\left(\mathrm{pg} \cdot \mathrm{m}^{-3}\right)$ & 0.66 & 6453 & 263 & 66.7 & 664 & n.d. & 3356 & 988 & 201 & 1078 \\
\hline Eu & $\left(\mathrm{pg} \cdot \mathrm{m}^{-3}\right)$ & 0.10 & 1446 & 59.1 & 14.7 & 149 & n.d. & 743 & 224 & 48.7 & 240 \\
\hline Gd & $\left(\right.$ pg.m $\left.\mathrm{m}^{-3}\right)$ & 0.87 & 6484 & 268 & 68.4 & 672 & n.d. & 3440 & 1026 & 215 & 1115 \\
\hline $\mathrm{Tb}$ & $\left(\right.$ pg.m $\left.{ }^{-3}\right)$ & 0.07 & 828 & 34.4 & 8.82 & 86.1 & n.d. & 438 & 131 & 26.8 & 142 \\
\hline Dy & $\left(\right.$ pg. $\left.\mathrm{m}^{-3}\right)$ & 0.39 & 4289 & 182 & 46.8 & 448 & n.d. & 2289 & 684 & 147 & 742 \\
\hline Ho & $\left(\mathrm{pg} \cdot \mathrm{m}^{-3}\right)$ & 0.09 & 810 & 34.6 & 8.96 & 84.7 & n.d. & 435 & 130 & 27.8 & 141 \\
\hline Er & $\left(\right.$ pg.m $\left.{ }^{-3}\right)$ & 0.29 & 2385 & 101 & 26.2 & 249 & n.d. & 1285 & 384 & 81.2 & 416 \\
\hline $\mathrm{Tm}$ & $\left(\right.$ pg.m $\left.{ }^{-3}\right)$ & 0.05 & 340 & 14.5 & 3.79 & 35.6 & n.d. & 183 & 54.9 & 11.7 & 59.5 \\
\hline $\mathrm{Yb}$ & $\left(\right.$ pg.m $\left.\mathrm{m}^{-3}\right)$ & 0.24 & 2191 & 93.1 & 24.3 & 228 & n.d. & 1193 & 355 & 76.0 & 386 \\
\hline Lu & $\left(\right.$ pg. $\left.\mathrm{m}^{-3}\right)$ & 0.04 & 315 & 13.6 & 3.59 & 33.0 & n.d. & 172 & 51.6 & 11.2 & 56.0 \\
\hline $\mathrm{Pb}$ & (ng. $\mathrm{m}^{-3}$ ) & 0.03 & 18.9 & 2.09 & 1.19 & 2.50 & n.d. & 17.6 & 4.28 & 2.24 & 3.98 \\
\hline Th & (ng. $\mathrm{m}^{-3}$ ) & 0.001 & 8.92 & 0.37 & 0.10 & 0.92 & n.d. & 4.43 & 1.30 & 0.27 & 1.40 \\
\hline U & $\left(\right.$ pg.m $\left.{ }^{-3}\right)$ & 0.80 & 2218 & 97.4 & 31.1 & 229 & 1.71 & 1102 & 333 & 91.0 & 355 \\
\hline
\end{tabular}




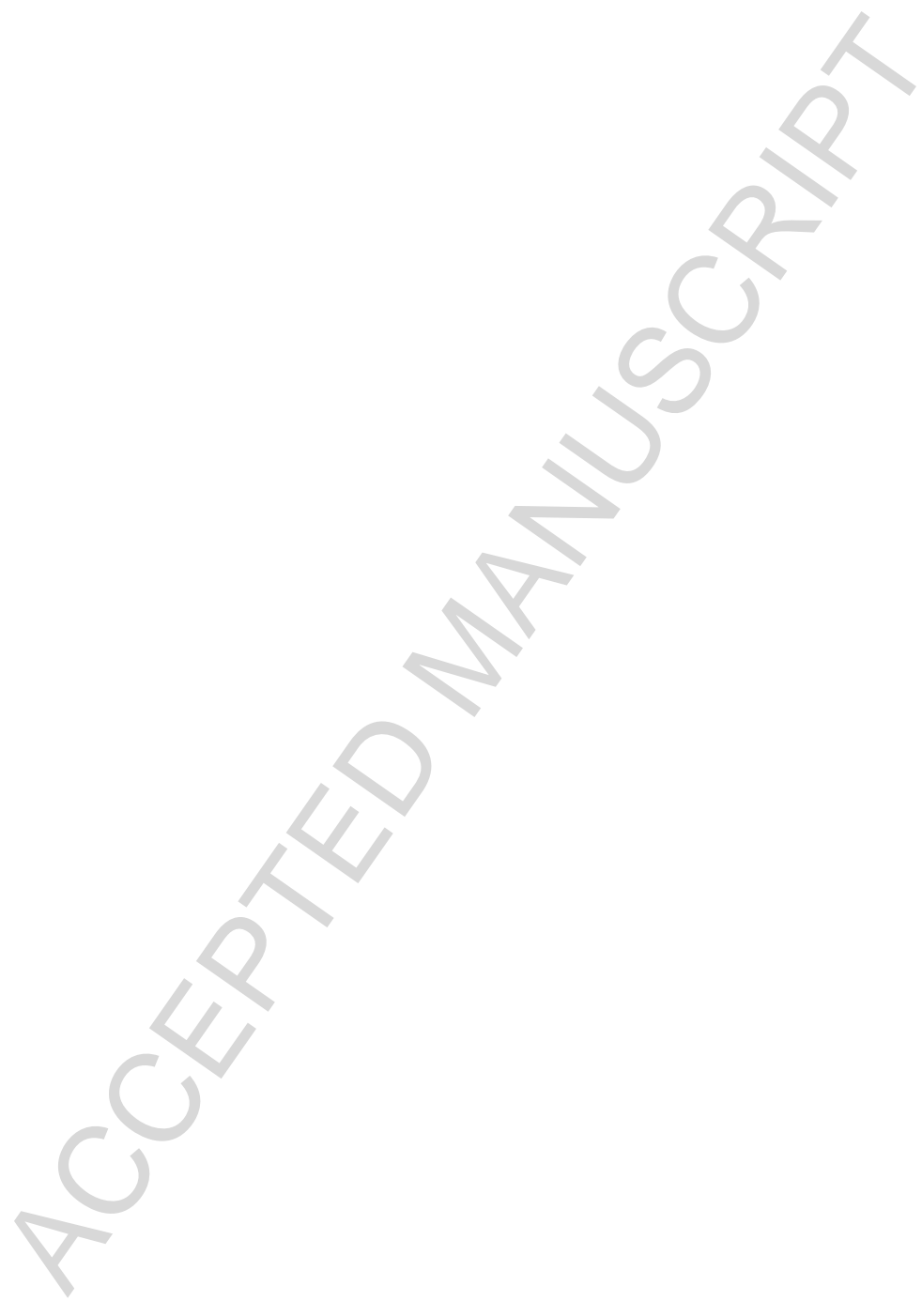


Table 3. Mean mineral composition of aerosols with North African origins, including maximum contributions for our study. ${ }^{1}$ Aerosols collected during dust events at Sal, Cape Verde, $1974 .{ }^{2}$ Aerosols collected during dust events in Montseny, Spain between 1984 and 1992. ${ }^{3}$ Aerosols collected during dust events at CVAO, Cape Verde, in December 2007 and January 2008.

\begin{tabular}{|c|c|c|c|c|c|c|c|c|c|c|}
\hline & Quartz & Calcite & $\begin{array}{l}\text { Total } \\
\text { Clays }\end{array}$ & $\begin{array}{l}\text { Mica / } \\
\text { Illite }\end{array}$ & Kaolin & Chlorite & $\begin{array}{c}\text { Mont- } \\
\text { morillonite }\end{array}$ & $\begin{array}{c}\text { Pyro- } \\
\text { phyllite }\end{array}$ & $\begin{array}{l}\text { Micro- } \\
\text { cline }\end{array}$ & $\begin{array}{l}\text { Plagio- } \\
\text { clase }\end{array}$ \\
\hline \multicolumn{11}{|l|}{ This study } \\
\hline Max & $36.4 \%$ & $90.7 \%$ & $84.7 \%$ & $53.2 \%$ & $57.6 \%$ & $23.3 \%$ & $0.3 \%$ & $61.7 \%$ & & \\
\hline Mean (n=33) & $15.0 \%$ & $28.4 \%$ & $52.0 \%$ & $26.4 \%$ & & $6.9 \%$ & $0.02 \%$ & $4.7 \%$ & & \\
\hline \multicolumn{11}{|l|}{$\begin{array}{l}\text { Glacuum and } \\
\text { Prospero (1980) }\end{array}$} \\
\hline Mean $(n=3)^{1}$ & $19.6 \%$ & $8.2 \%$ & $64.6 \%$ & $53.8 \%$ & $6.6 \%$ & $4.3 \%$ & & & $2.2 \%$ & $5.4 \%$ \\
\hline \multicolumn{11}{|l|}{ Avila et al. (1997) } \\
\hline $\operatorname{Mean}(n=13)^{2}$ & $18 \%$ & $7.5 \%$ & $62.2 \%$ & & $7 \%$ & & & & & \\
\hline \multicolumn{11}{|l|}{$\begin{array}{c}\text { Jeong and } \\
\text { Achterberg (2014) }\end{array}$} \\
\hline $\operatorname{Mean}(n=2)^{3}$ & $8 \%$ & $2 \%$ & $81 \%$ & $72 \%$ & $6 \%$ & $3 \%$ & & & & $2 \%$ \\
\hline
\end{tabular}


Table 4. Selected mean elemental ratios in samples originating from specific African regions. Mean values are given with uncertainties of 1 standard deviation. Nss stands for non-sea salt. Significant differences $(p<0.05)$ between samples from Region 1 and Region 2 , and between those from Region 1 and Regions $2 \& 3$ are indicated in bold. There were no statistically significant differences between samples originating from Region 2 and Regions $2 \& 3$.

\begin{tabular}{|llll|}
\hline & $\begin{array}{c}\text { Sahel } \\
\text { (Region 1) }\end{array}$ & $\begin{array}{c}\text { South / Central Sahara } \\
\text { (Region 2) }\end{array}$ & $\begin{array}{c}\text { NW \& South / Central Sahara } \\
\text { (Regions 2 \& 3) }\end{array}$ \\
\hline $\mathbf{N}^{\circ}$ Samples & 21 & 11 & 13 \\
nss Mg/Al & $\mathbf{0 . 3 0} \pm \mathbf{0 . 1 9}$ & $\mathbf{0 . 1 7} \pm \mathbf{0 . 0 5}$ & $\mathbf{0 . 1 6} \pm \mathbf{0 . 0 4}$ \\
nss K/Al & $\mathbf{0 . 2 3} \pm \mathbf{0 . 0 6}$ & $\mathbf{0 . 2 0} \pm \mathbf{0 . 0 3}$ & $0.20 \pm 0.03$ \\
nss Ca/Al & $0.57 \pm 0.18$ & $0.50 \pm 0.23$ & $0.52 \pm 0.11$ \\
Fe/nss Ca & $1.1 \pm 0.4$ & $1.3 \pm 0.5$ & $1.2 \pm 0.3$ \\
nss K/nssCa & $\mathbf{0 . 4 8} \pm \mathbf{0 . 1 3}$ & $0.46 \pm 0.13$ & $\mathbf{0 . 3 9} \pm \mathbf{0 . 1 0}$ \\
Fe/Al & $0.58 \pm 0.04$ & $0.56 \pm 0.05$ & $0.58 \pm 0.04$ \\
\hline
\end{tabular}

Table 5. Selected anthropogenic mean elemental ratios in samples originating from specific African regions. Mean values are given with uncertainties of 1 standard deviation. Significant differences $(p<$ 0.05) between samples from Region 1 and Region 2, and between those from Region 1 and Regions 2 \& 3 are indicated in bold. There were no statistically significant differences between samples originating from Region 2 and Regions $2 \& 3$.

\begin{tabular}{|cccc|}
\hline Region & $\begin{array}{c}\text { Sahel } \\
\text { (Region 1) }\end{array}$ & $\begin{array}{c}\text { South / Central Sahara } \\
\text { (Region 2) }\end{array}$ & $\begin{array}{c}\text { NW \& South / Central Sahara } \\
\text { (Regions 2 \& 3) }\end{array}$ \\
$\mathrm{N}^{\circ}$ Samples & 33 & 13 & 14 \\
\hline $\mathrm{V} / \mathrm{Al}$ & $\mathbf{0 . 0 0 4 4} \pm \mathbf{0 . 0 0 2 4}$ & $0.0028 \pm 0.0026$ & $\mathbf{0 . 0 0 2 1} \pm \mathbf{0 . 0 0 0 8}$ \\
$\mathrm{Ni} / \mathrm{Al}$ & $\mathbf{0 . 0 0 2 0} \pm \mathbf{0 . 0 0 1 1}$ & $0.0013 \pm 0.0018$ & $\mathbf{0 . 0 0 0 8} \pm \mathbf{0 . 0 0 0 5}$ \\
$\mathrm{Cu} / \mathrm{Al}$ & $\mathbf{0 . 0 0 0 9 9} \pm \mathbf{0 . 0 0 0 5 0}$ & $0.00068 \pm 0.00058$ & $\mathbf{0 . 0 0 0 5 5} \pm \mathbf{0 . 0 0 0 2 0}$ \\
$\mathrm{Zn} / \mathrm{Al}$ & $\mathbf{0 . 0 0 9 9} \pm \mathbf{0 . 0 0 8 8}$ & $0.0055 \pm 0.0090$ & $\mathbf{0 . 0 0 2 5} \pm \mathbf{0 . 0 0 2 2}$ \\
$\mathrm{Cd} / \mathrm{Al}$ & $\mathbf{0 . 0 0 0 0 4 8} \pm \mathbf{0 . 0 0 0 0 3 4}$ & $\mathbf{0 . 0 0 0 0 1 8} \pm \mathbf{0 . 0 0 0 0 1 7}$ & $\mathbf{0 . 0 0 0 0 1 3} \pm \mathbf{0 . 0 0 0 0 1 6}$ \\
$\mathrm{Pb} / \mathrm{Al}$ & $\mathbf{0 . 0 0 2 5} \pm \mathbf{0 . 0 0 1 4}$ & $\mathbf{0 . 0 0 1 1} \pm \mathbf{0 . 0 0 1 1}$ & $\mathbf{0 . 0 0 1 3} \pm \mathbf{0 . 0 0 1 4}$ \\
\hline
\end{tabular}


Figures

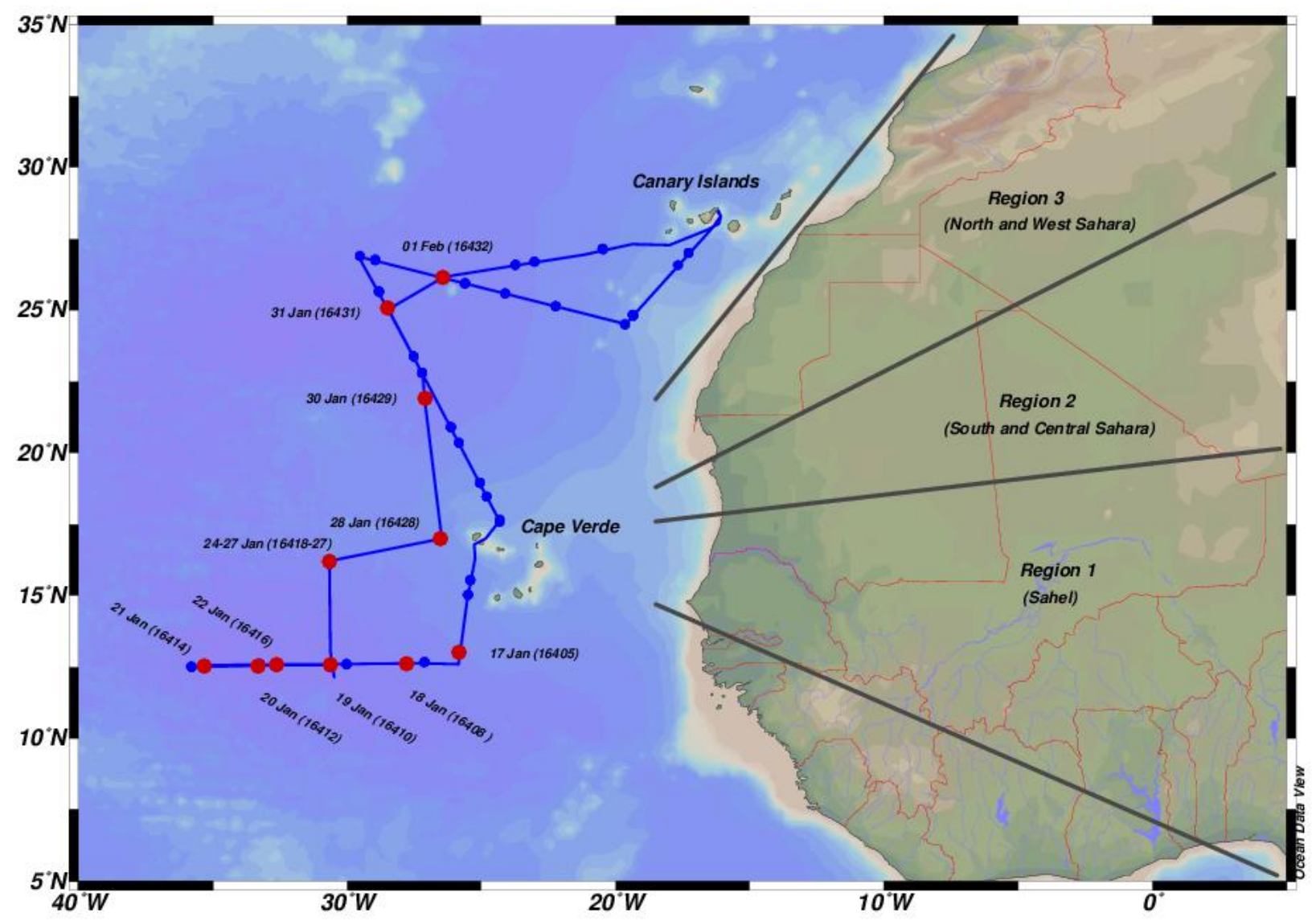


Figure1. Cruise track in northeast Atlantic Ocean as blue line for D326 aboard RRS Discovery (8 January - 4 February 2008). Stations are marked in red together with their station numbers. Black lines on and along African continent are from scheme used by (Chiapello et al., 1997) to classify air-masses originating from the African continent. Region 1: Sahel; Region 2: South and Central Sahara; Region 3: North and West Sahara. 


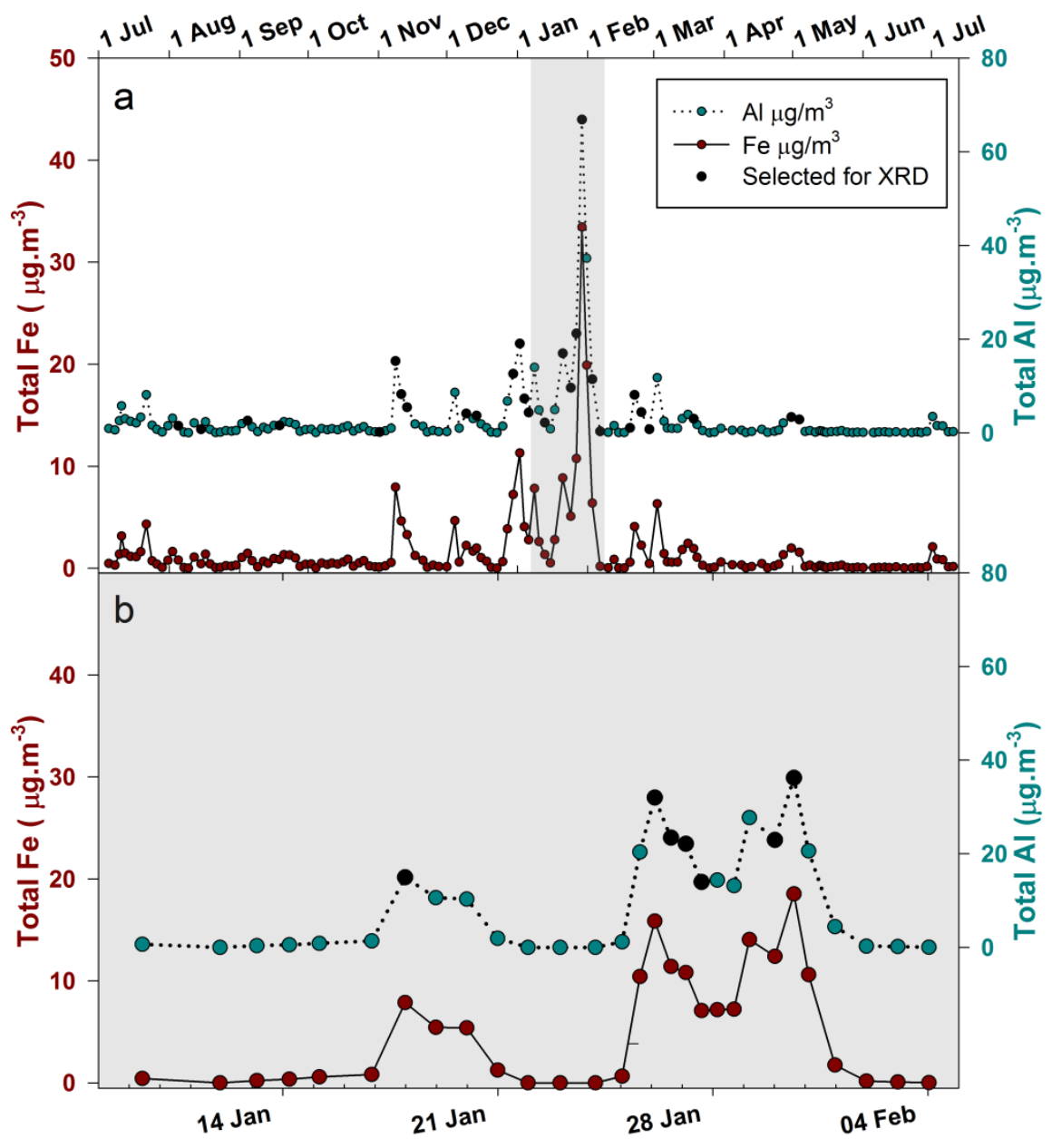


Figure 2. a) Total Fe and Al atmospheric concentrations observed at the CVAO in the period between 2 July 2007 and 11 July 2008. Grey shading indicates cruise period. b) Total Fe and Al concentrations from samples collected aboard RRS Discovery during a research cruise (D326) in the eastern tropical and sub-tropical North Atlantic between 8 January and 4 February 2008. In both panels, the $y$ axis for Al is offset to facilitate viewing of the Fe data.

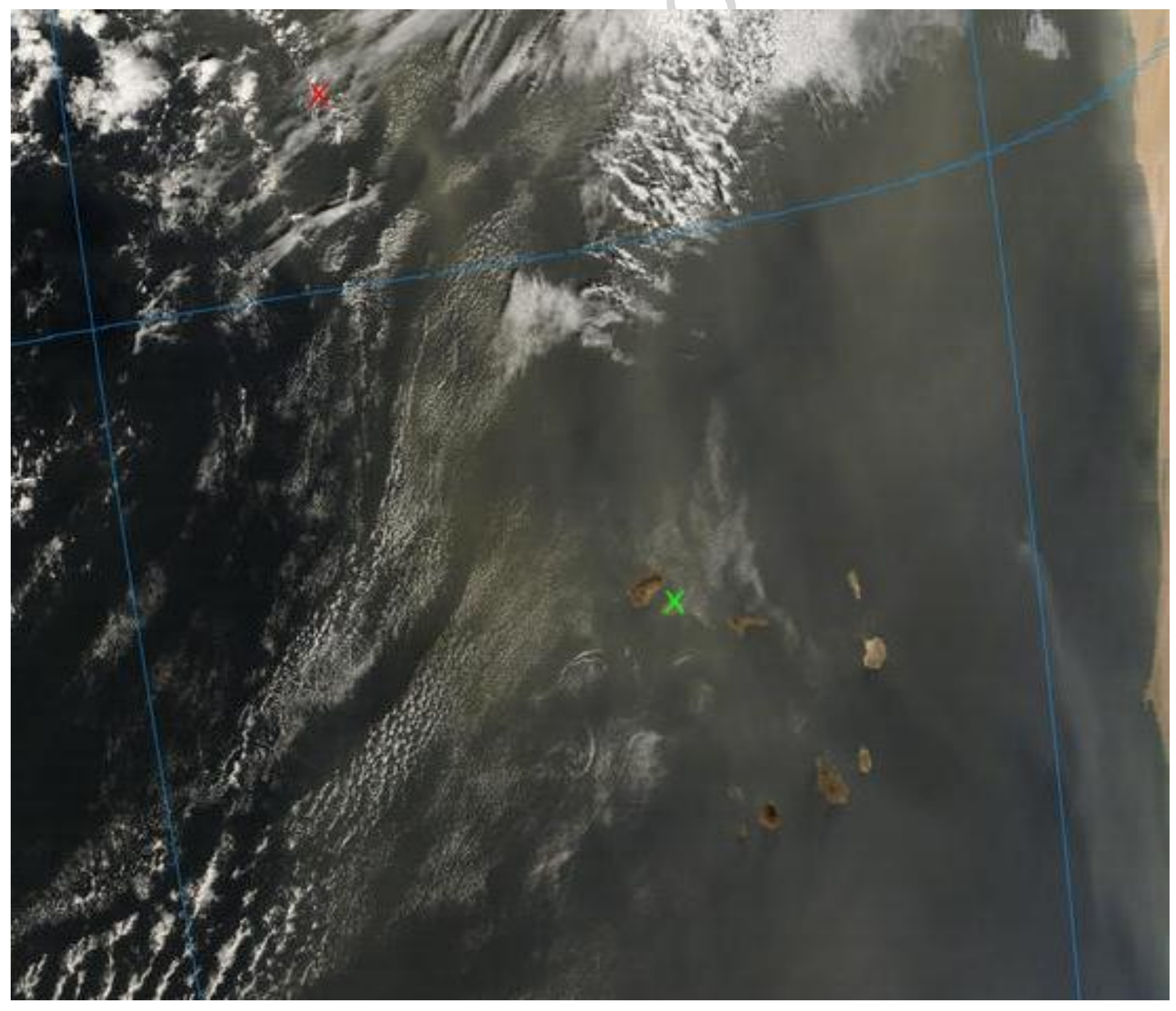


Figure 3. Terra/MODIS true colour image of Cape Verde region taken at 12:25 UTC 30 Feb 2008. The approximate locations of the CVAO (green) and RRS Discovery (red) are indicated by crosses. Source: NASA/GSFC/Earth Science Data and Information System (ESDIS) 


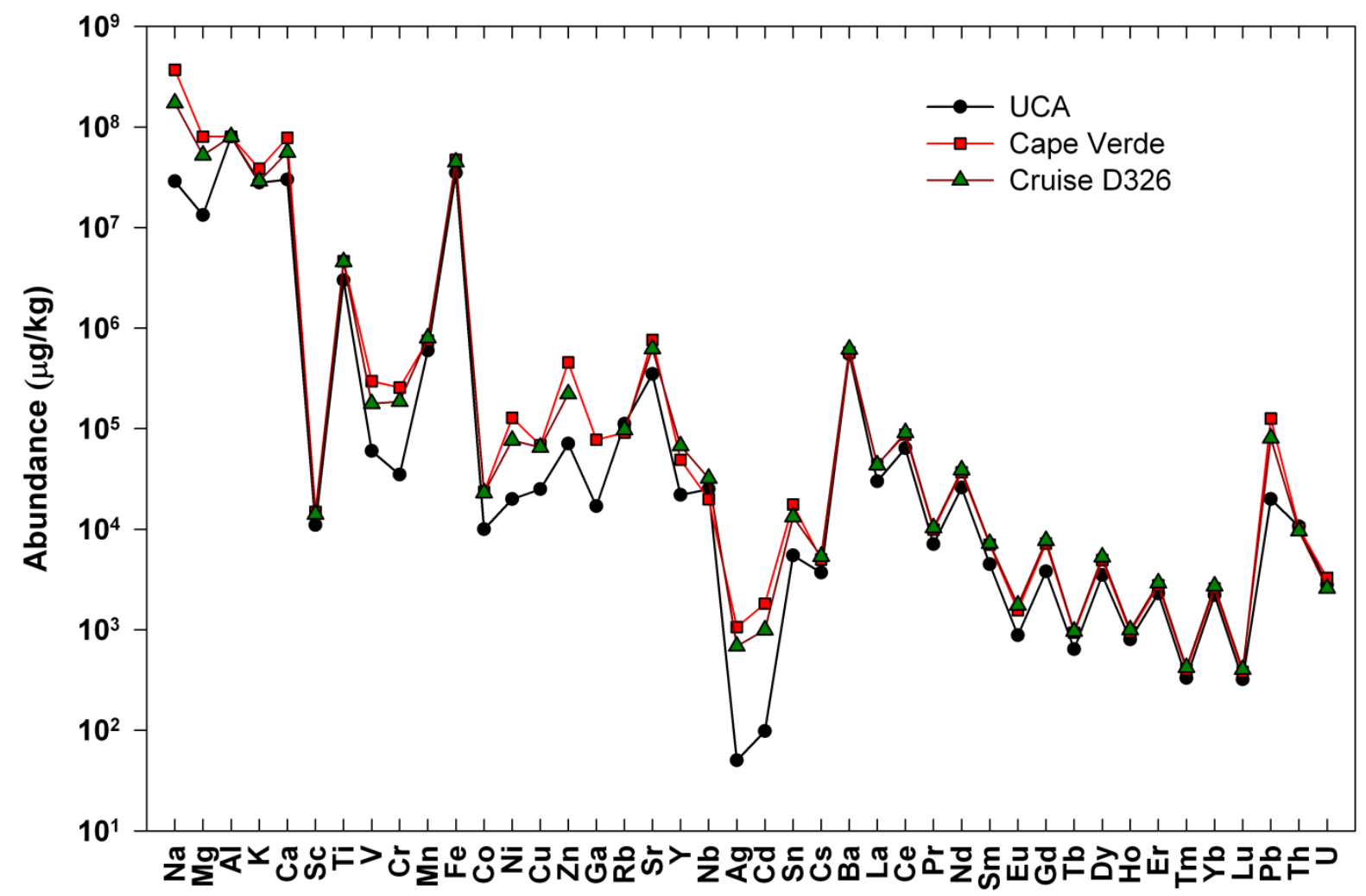

Figure 4. Mean composition of samples collected at CVAO and during cruise D326 plotted together with mean upper crustal composition (UCA) (Taylor and McLennan, 1995). All values have been normalised to $8.04 \%$ wt. Al. 


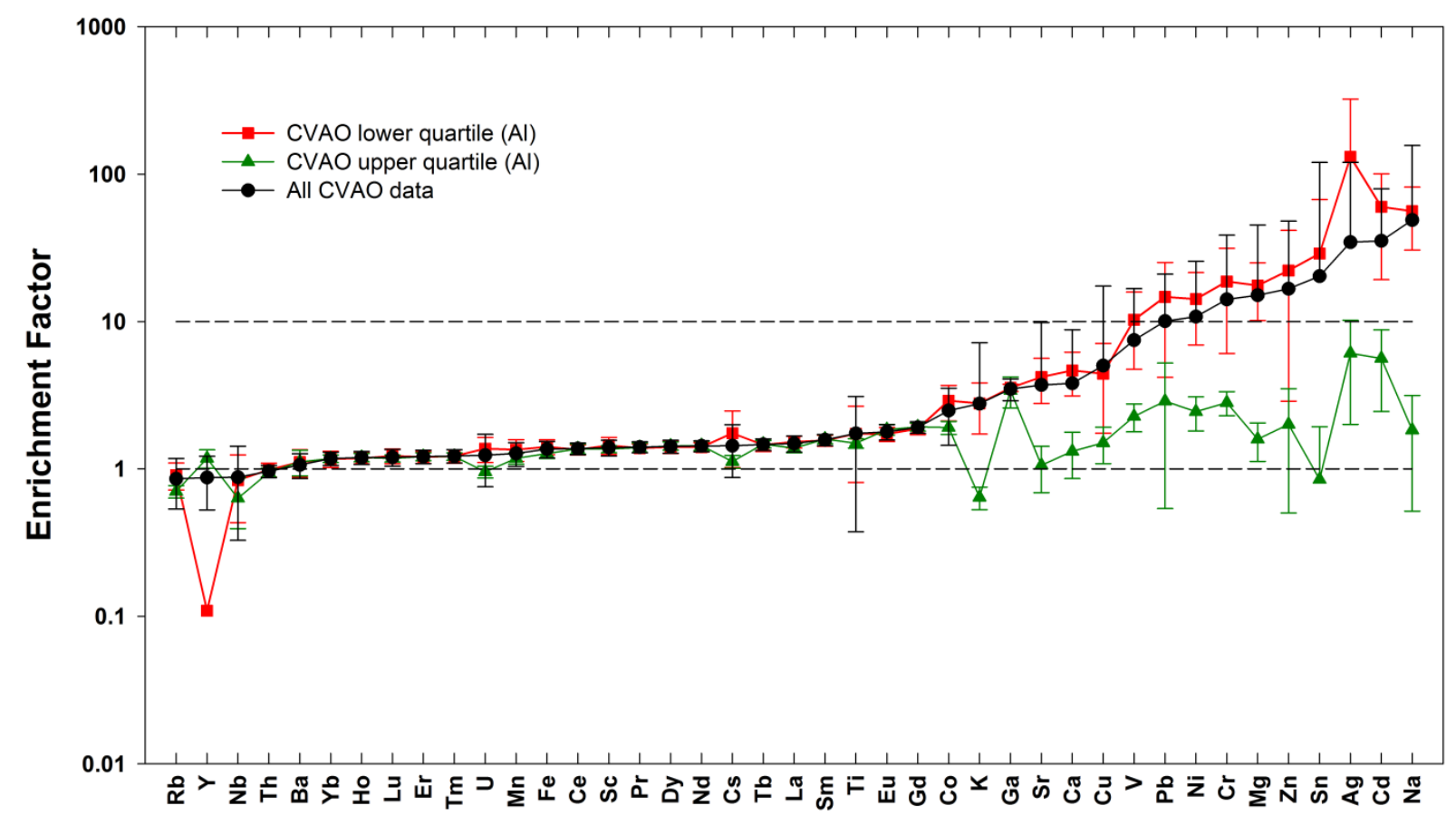

Figure 5. Mean crustal enrichment factors for total elemental concentrations determined at CVAO, illustrating the difference in enrichment factors between the upper $\left(\mathrm{T} 25-[\mathrm{Al}]>2.4 \mu \mathrm{g} \cdot \mathrm{m}^{-3}\right)$ and lower $\left(\mathrm{B} 25-[\mathrm{Al}]<0.23 \mu \mathrm{g} \cdot \mathrm{m}^{-3}\right.$ ) quartiles of the dataset (ranked in order of atmospheric total Al concentration). Samples with $<1 \mu \mathrm{g} \cdot \mathrm{m}^{-3}$ TSP equivalent $\left([\mathrm{Al}]<0.080 \mu \mathrm{g} \cdot \mathrm{m}^{-3}\right)$ have been excluded from the calculations. Enrichment factors of 1 and 10 are marked by dashed lines. 


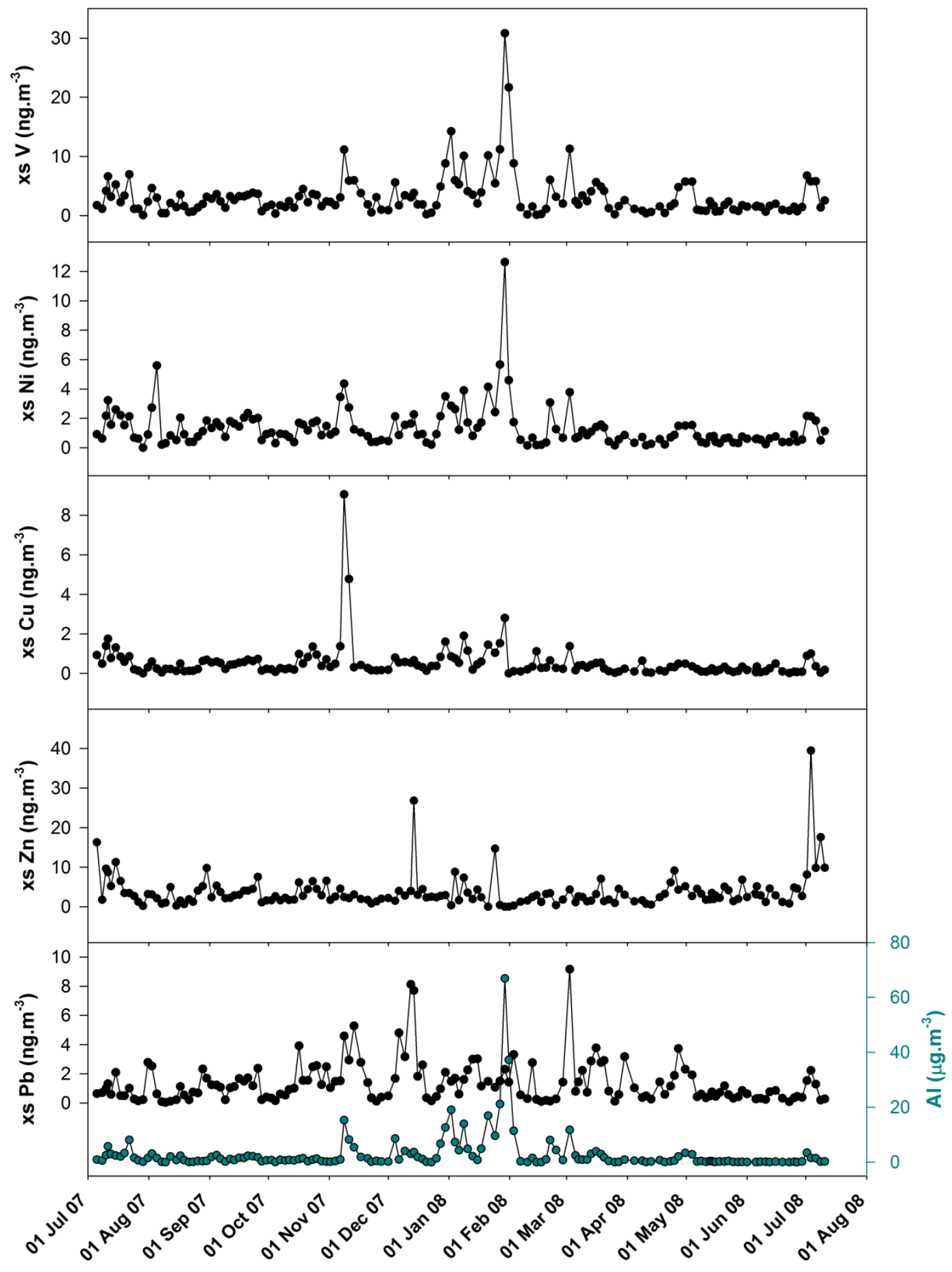


Figure 6. Temporal trends of excess atmospheric concentrations of selected pollutant aerosol species at CVAO. Values are excess concentrations, calculated by subtracting the crustal component from the value total digestion (using total Al concentrations and UCA for the element in question). Total Al concentrations (in cyan) are included for reference.

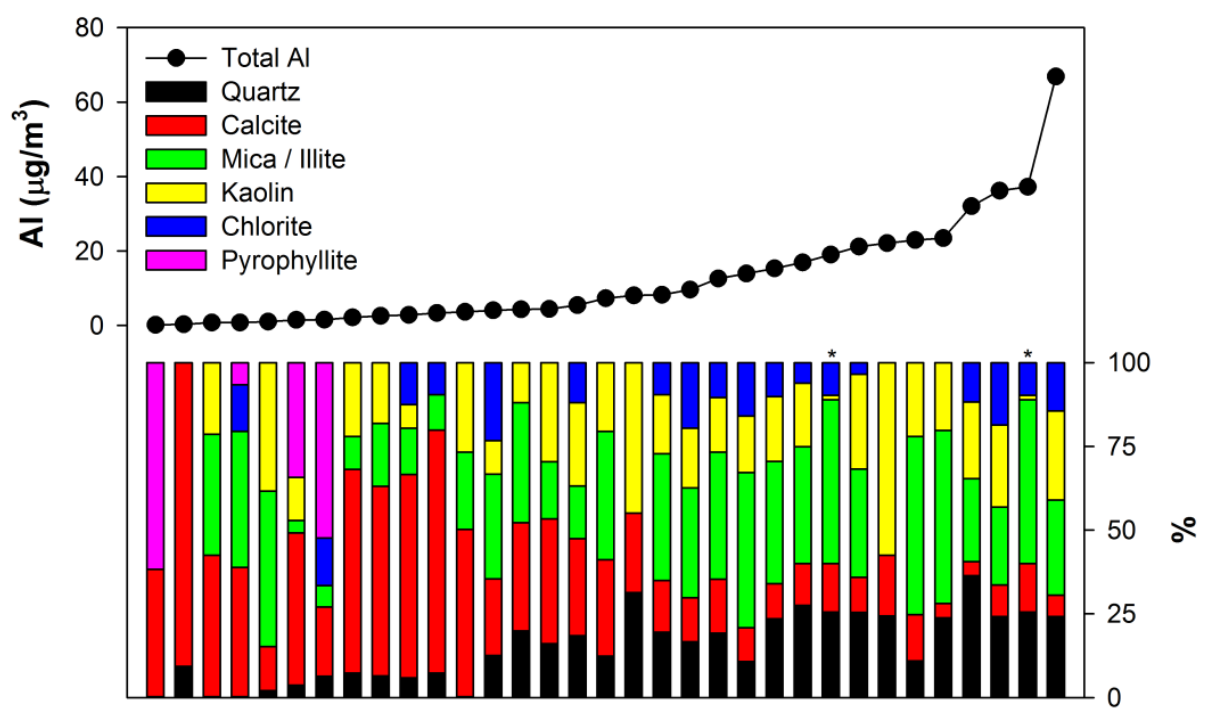

Figure 7. Mineral composition (\% wt) of selected samples at CVAO, in order of increasing total Al concentration. Two samples indicated by asterisks contain $0.3 \%$ montmorillonite, which is not shown in the bar. 


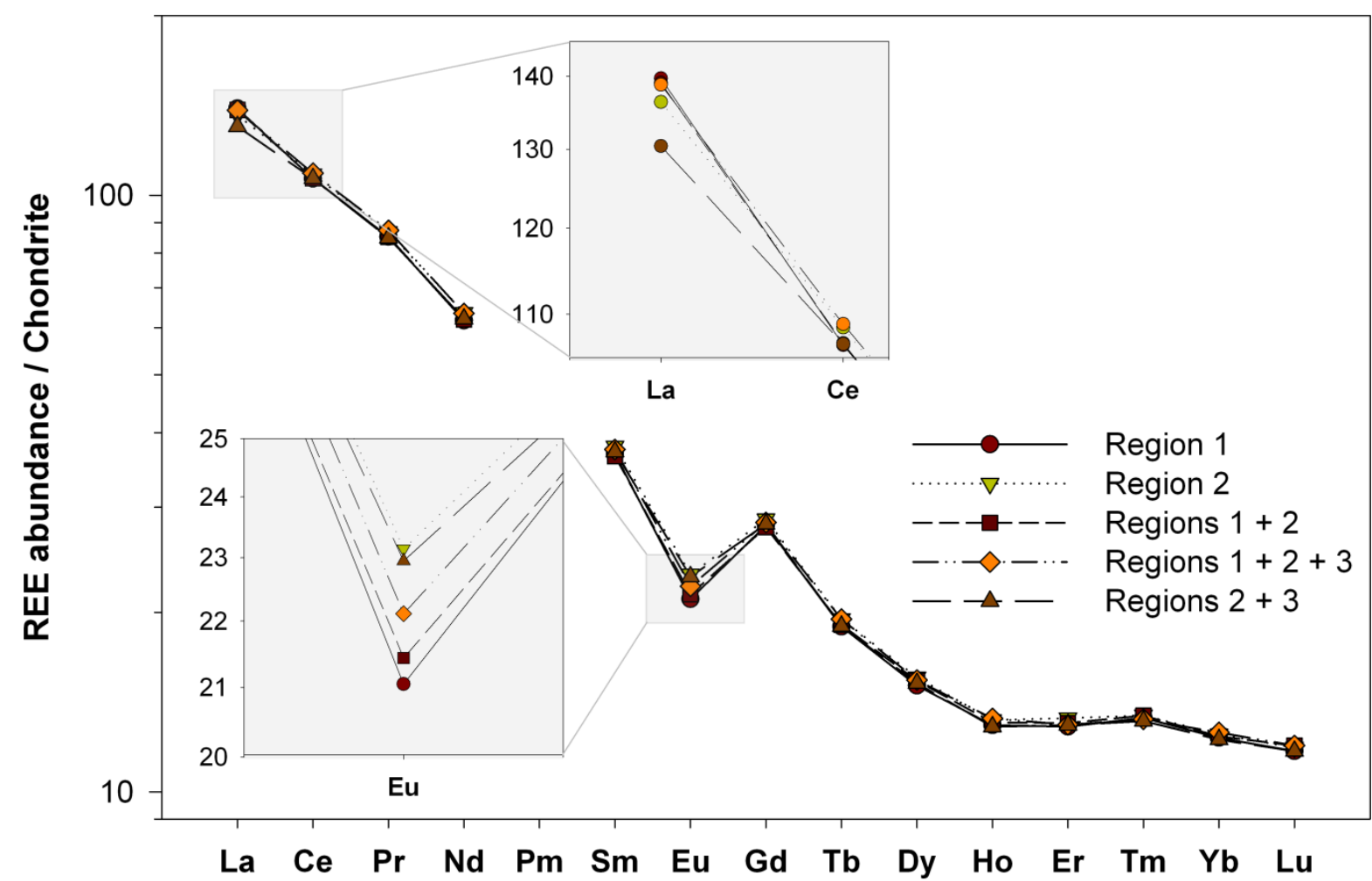

Figure 8. Chondrite normalised rare earth element (REE) patterns for samples collected at the CVAO between 2 July 2007 and 11 July 2008. Mean values are plotted from 5 groups corresponding to different source regions identified from air-mass back-trajectories (labelled according to Chiapello et al., 1997). 16 samples containing very low concentrations ( $\mathrm{Al}<3.8 \mu \mathrm{g} /$ filter) have been excluded. 


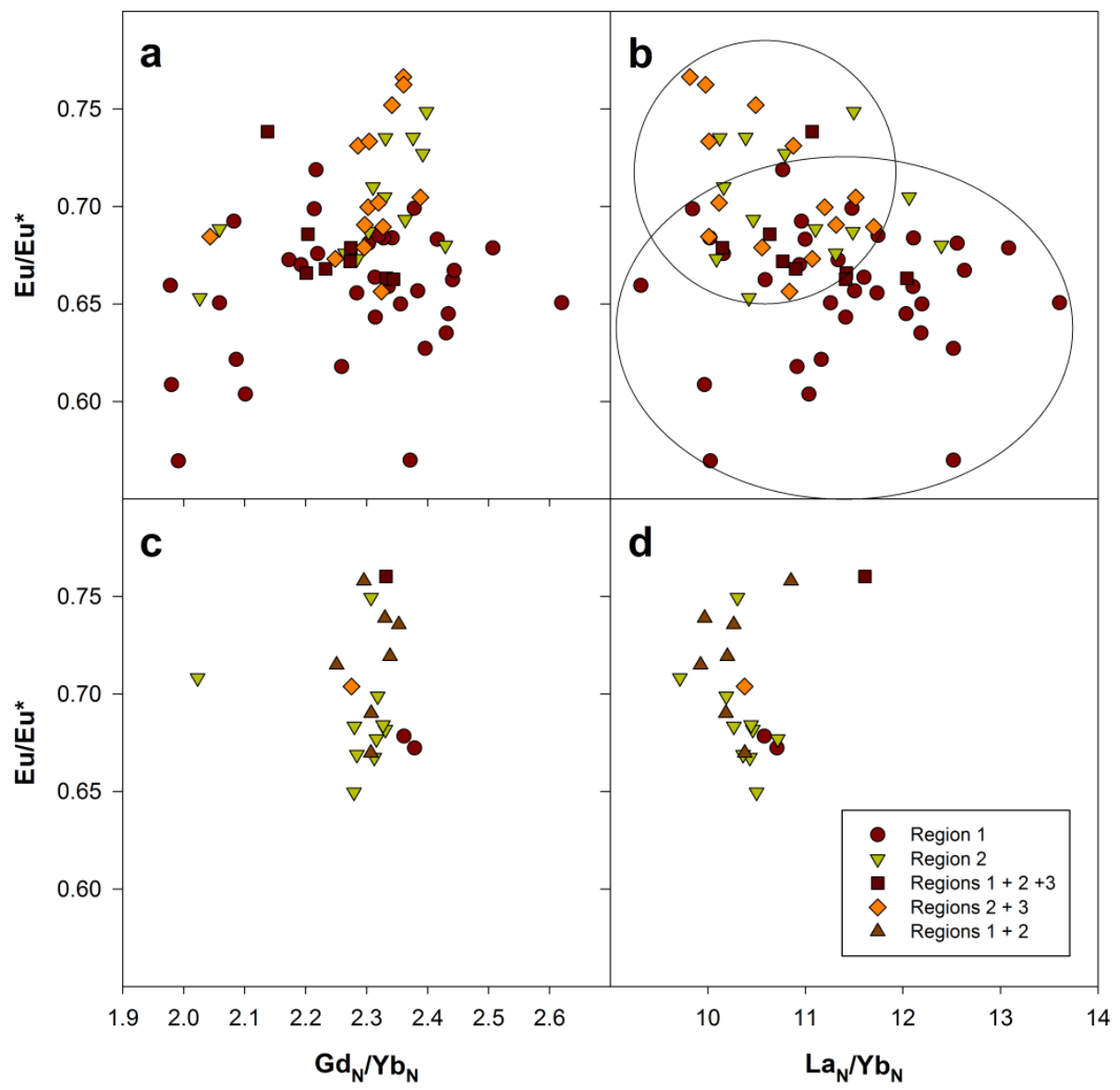

Figure 9. a) Ratios of EuN/Eu* vs $\mathrm{Gd}_{N} / \mathrm{Yb}_{N}$ for individual samples collected at the CVAO between 2 July 2007 and 11 July 2008. Samples associated with Regions $1+2$, and with very low concentrations (Al $<3.8 \mu \mathrm{g} /$ filter) have been excluded. b) Ratios of $\mathrm{Eu}_{N} / \mathrm{Eu}^{*} \mathrm{vs} \mathrm{La}_{N} / \mathrm{Yb}_{N}$ ratio for individual samples collected at the CVAO between 2 July 2007 and 11 July 2008. Samples associated with Regions $1+2$, and with very low concentrations ( $\mathrm{Al}<3.8 \mu \mathrm{g} /$ filter) have been excluded. Samples from Region 1 and Regions $2+3$ have been circled.c) Ratios of $\mathrm{Eu}_{N} / \mathrm{Eu}^{*} \mathrm{vs}_{\mathrm{Gd}} / \mathrm{Yb}_{\mathrm{N}}$ for individual samples collected during research cruise D326 between 8 January and 4 February 2008. Eight samples associated with predominantly marine

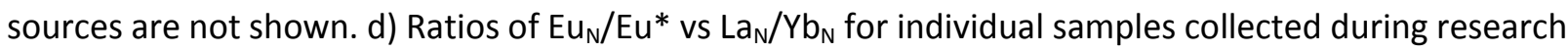


cruise D326 between 8 January and 4 February 2008. Eight samples associated with predominantly marine sources are not shown.

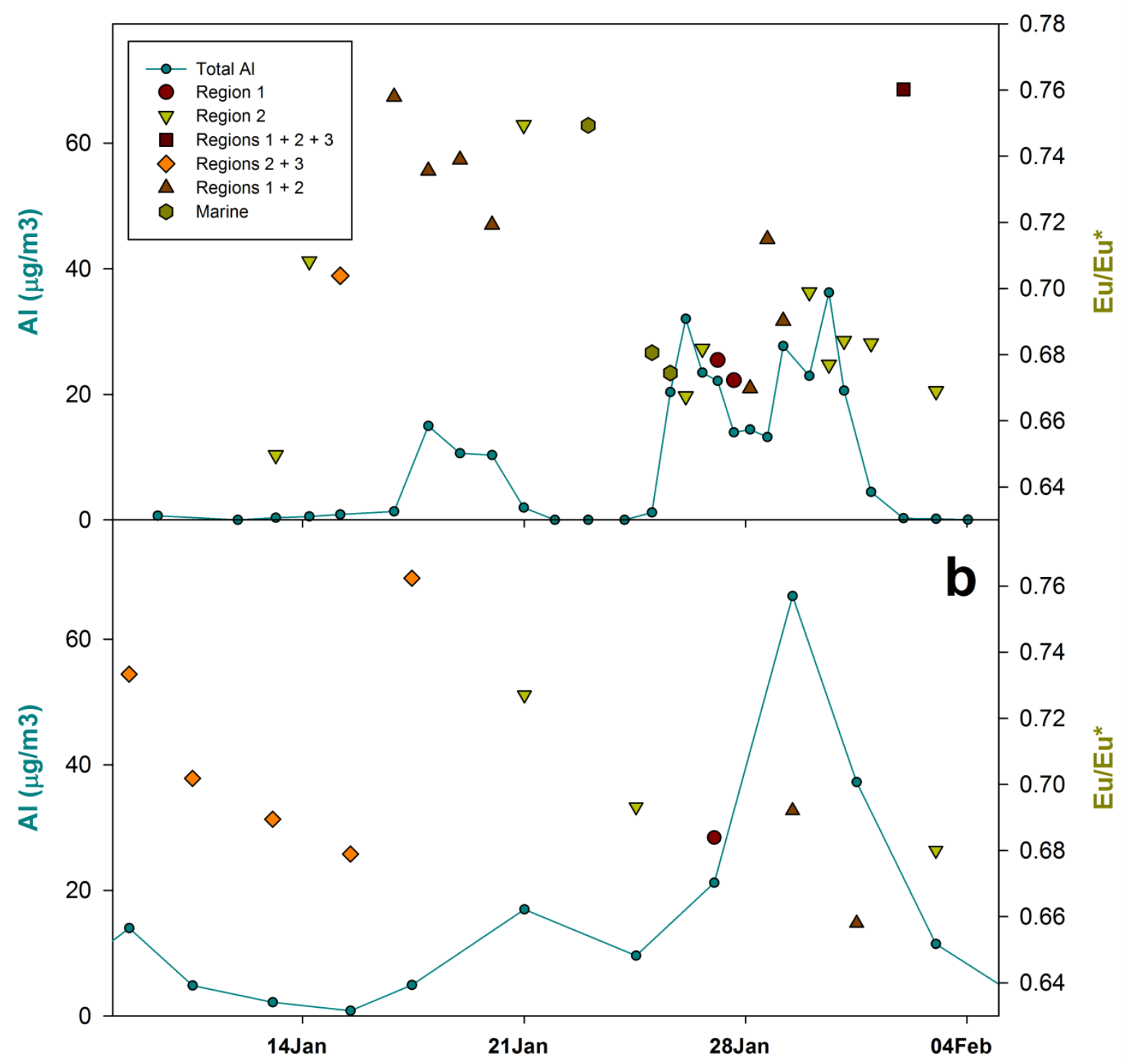

Figure 10. a) Plot of Eu $/ \mathrm{Eu}^{*}$ vs date for individual samples collected during research cruise D326 between 8 January and 4 February 2008. Total atmospheric Al concentration is included to indicate the 
timing of the dust events encountered. b) Plot of $\mathrm{Eu}_{N} / \mathrm{Eu}^{*}$ vs date for individual samples collected at CVAO during the period of the research cruise.

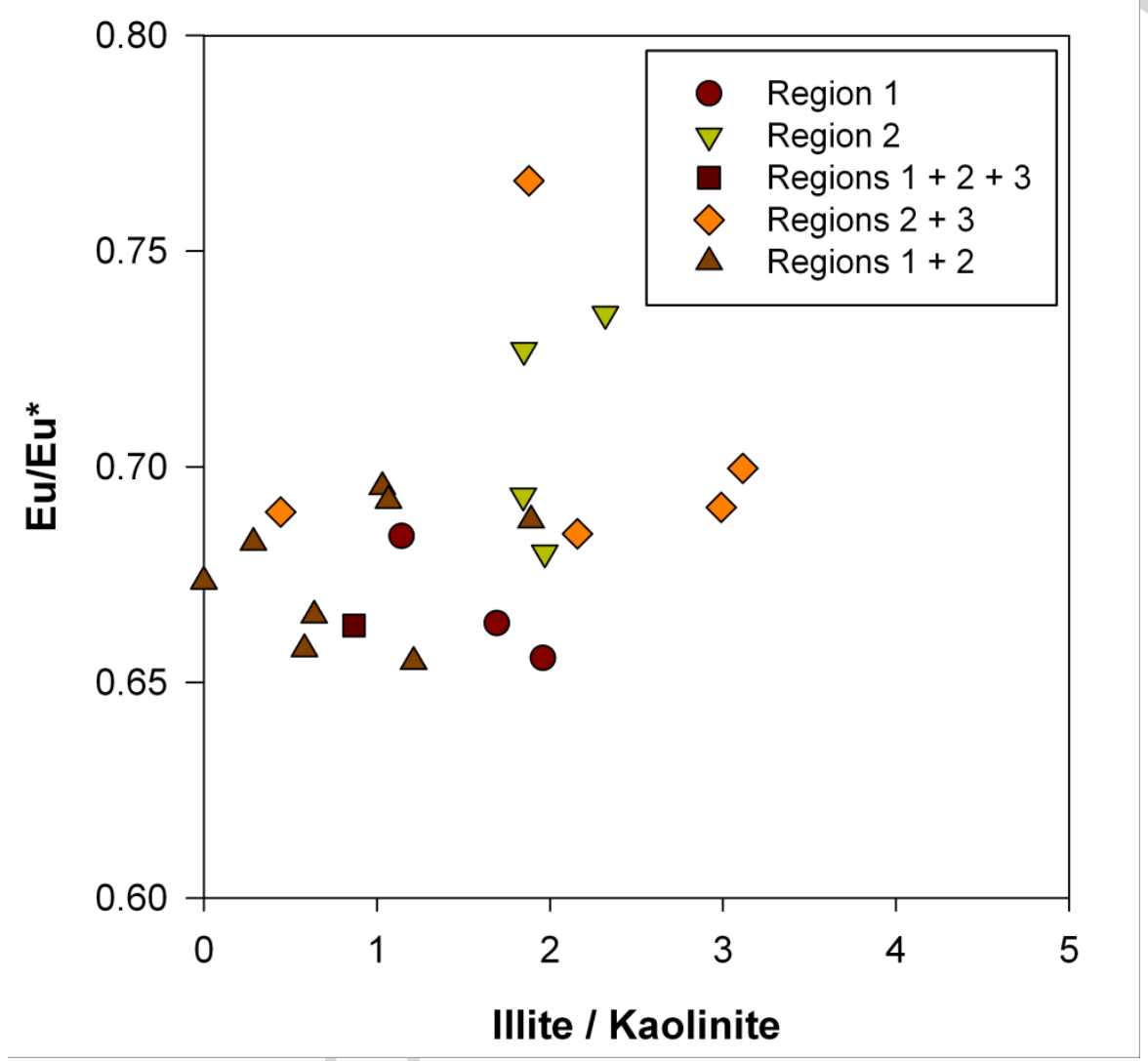

Figure 11. Illite / kaolinite ratios for selected samples at CVAO, for which XRD measurements were obtained, plotted against the Europium anomaly, $\mathrm{Eu}_{\mathrm{N}} / \mathrm{Eu}^{*}$. 


\section{References}

Aguilar-Islas, A.M., Wu, J., Rember, R., Johansen, A.M. and Shank, L.M., 2010. Dissolution of aerosolderived iron in seawater: Leach solution chemistry, aerosol type, and colloidal iron fraction. Marine Chemistry, 120(1-4): 25-33.

Astitha, M. et al., 2010. Modelling the chemically aged and mixed aerosols over the eastern central Atlantic Ocean - potential impacts. Atmospheric Chemistry and Physics, 10(13): 5797-5822.

Avila, A., Queralt-Mitjans, I. and Alarcón, M., 1997. Mineralogical composition of African dust delivered by red rains over northeastern Spain. Journal of Geophysical Research: Atmospheres, 102(D18): 21977-21996.

Baker, A.R. and Croot, P.L., 2010. Atmospheric and marine controls on aerosol iron solubility in seawater. Marine Chemistry, 120(1-4): 4-13.

Baker, A.R., Jickells, T.D., Witt, M. and Linge, K.L., 2006. Trends in the solubility of iron, aluminium, manganese and phosphorus in aerosol collected over the Atlantic Ocean. Marine Chemistry, 98(1): 43-58.

Baker, A.R. et al., 2007. Dry and wet deposition of nutrients from the tropical Atlantic atmosphere: Links to primary productivity and nitrogen fixation. Deep Sea Research Part I: Oceanographic Research Papers, 54(10): 1704-1720.

Buck, C.S., Landing, W.M., Resing, J.A. and Lebon, G.T., 2006. Aerosol iron and aluminium solubility in the northwest Pacific Ocean: Results from the 2002 IOC cruise. Geochemistry, Geophysics, Geosystems, 7(4).

Buck, C.S., Landing, W.M., Resing, J.A. and Measures, C.I., 2010. The solubility and deposition of aerosol Fe and other trace elements in the North Atlantic Ocean: Observations from the A16N CLIVAR/CO2 repeat hydrography section. Marine Chemistry, 120(1â€"4): 57-70.

Buck, C.S. and Paytan, A., 2012. Evaluation of commonly used filter substrates for the measurement of aerosol trace element solubility. Limnology and Oceanography: Methods, 10(10): 790-806.

Caquineau, S., Gaudichet, A., Gomes, L. and Legrand, M., 2002. Mineralogy of Saharan dust transported over northwestern tropical Atlantic Ocean in relation to source regions. Journal of Geophysical Research: Atmospheres, 107(D15).

Caquineau, S., Gaudichet, A., Gomes, L., Magonthier, M.-C. and Chatenet, B., 1998. Saharan dust: Clay ratio as a relevant tracer to assess the origin of soil-derived aerosols. Geophysical Research Letters, 25(7): 983-986.

Carlson, T.N. and Prospero, J.M., 1972. The Large-Scale Movement of Saharan Air Outbreaks over the Northern Equatorial Atlantic. Journal of Applied Meteorology, 11(2): 283-297.

Carpenter, L.J. et al., 2010. Seasonal characteristics of tropical marine boundary layer air measured at the Cape Verde Atmospheric Observatory. Journal of Atmospheric Chemistry, 67(2-3): 87-140.

Chavagnac, V. et al., 2007. Anti-Atlas Moroccan Chain as the source of lithogenic-derived micronutrient fluxes to the deep Northeast Atlantic Ocean. Geophysical Research Letters, 34(21).

Chennaux, G. and Dunoyer de Segonzac, G., 1967. Petrographic study of the pyrophyllite in the Silurian and Devonian of the Sahara, Algeria; distribution and origin. Bulletin du Service de la Carte Geologique d'Alsace et da Lorraine, 20(4): 195-209. 
Chester, R., Nimmo, M. and Preston, M.R., 1999. The trace metal chemistry of atmospheric dry deposition samples collected at Cap Ferrat: a coastal site in the Western Mediterranean. Marine Chemistry, 68(1-2): 15-30.

Chiapello, I. et al., 1997. Origins of African dust transported over the northeastern tropical Atlantic. Journal of Geophysical Research: Atmospheres, 102(D12): 13701-13709.

Chiapello, I. et al., 1995. An additional low layer transport of Sahelian and Saharan dust over the northeastern Tropical Atlantic. Geophysical Research Letters, 22(23): 3191-3194.

Dall'Osto, M. et al., 2010. Variation of the mixing state of Saharan dust particles with atmospheric transport. Atmospheric Environment, 44(26): 3135-3146.

Draxler, R.R., 1999. HYSPLIT4 user's guide. ERL ARL-230, NOAA Air Resources Laboratory, Silver Spring, MD.

Draxler, R.R. and Hess, G.D., 1997. Description of the HYSPLIT_4 modeling system. ARL-224, NOAA Air Resources Laboratory, Silver Spring, MD.

Draxler, R.R. and Hess, G.D., 1998. An overview of the HYSPLIT_4 modelling system for trajectories, dispersion and deposition. Australian Meteorological Magazine, 47: 295-308.

Duce, R.A. and Tindale, N.W., 1991. Atmospheric transport of iron and its deposition in the ocean. Limnology and Oceanography, 36(8): 1715-1726.

Fomba, K.W., Müller, K., van Pinxteren, D. and Herrmann, H., 2013. Aerosol size-resolved trace metal composition in remote northern tropical Atlantic marine environment: case study Cape Verde islands. Atmospheric Chemistry and Physics, 13(9): 4801-4814.

Formenti, P., Elbert, W., Maenhaut, W., Haywood, J. and Andreae, M.O., 2003. Chemical composition of mineral dust aerosol during the Saharan Dust Experiment (SHADE) airborne campaign in the Cape Verde region, September 2000. Journal of Geophysical Research: Atmospheres, 108(D18).

Gangoiti, G., Alonso, L., Navazo, M., García, J.A. and Millán, M.M., 2006. North African soil dust and European pollution transport to America during the warm season: Hidden links shown by a passive tracer simulation. Journal of Geophysical Research: Atmospheres, 111(D10).

Gelado-Caballero, M.D. et al., 2012. Long-term aerosol measurements in Gran Canaria, Canary Islands: Particle concentration, sources and elemental composition. Journal of Geophysical Research: Atmospheres, 117(D3).

Glaccum, R.A. and Prospero, J.M., 1980. Saharan aerosols over the tropical North Atlantic - Mineralogy. Marine Geology, 37(3-4): 295-321.

Götze, J., Plötze, M., Graupner, T., Hallbauer, D.K. and Bray, C.J., 2004. Trace element incorporation into quartz: A combined study by ICP-MS, electron spin resonance, cathodoluminescence, capillary ion analysis, and gas chromatography 1. Geochimica et Cosmochimica Acta, 68(18): 3741-3759.

Goudie, A.S. and Middleton, N.J., 2006. Desert dust in the global system. Springer, 288 pp.

Guieu, C., Loÿe-Pilot, M.D., Ridame, C. and Thomas, C., 2002. Chemical characterization of the Saharan dust end-member: Some biogeochemical implications for the western Mediterranean Sea. Journal of Geophysical Research: Atmospheres, 107(D15).

Herut, B., Nimmo, M., Medway, A., Chester, R. and Krom, M.D., 2001. Dry atmospheric inputs of trace metals at the Mediterranean coast of Israel (SE Mediterranean): sources and fluxes. Atmospheric Environment, 35(4): 803-813.

Hill, P.G., Zubkov, M.V. and Purdie, D.A., 2010. Differential responses of Prochlorococcus and SAR11dominated bacterioplankton groups to atmospheric dust inputs in the tropical Northeast Atlantic Ocean. FEMS Microbiology Letters, 306(1): 82-89. 
Hill, R.J., Tsambourakis, G. and Madsen, I.C., 1993. Improved Petrological Modal Analyses from X-ray Powder Diffraction Data by use of the Rietveld Method I. Selected Igneous, Volcanic, and Metamorphic Rocks. Journal of Petrology, 34(5): 867-900.

Hillier, S., 2000. Accurate quantitative analysis of clay and other minerals in sandstones by XRD: comparison of a Rietveld and a reference intensity ratio (RIR) method and the importance of sample preparation. Clay Minerals, 35(1): 291-302.

Hsu, S.-C. et al., 2010. Sources, solubility, and dry deposition of aerosol trace elements over the East China Sea. Marine Chemistry, 120(1-4): 116-127.

Jeong, G.Y. and Achterberg, E.P., 2014. Chemistry and mineralogy of clay minerals in Asian and Saharan dusts and the implications for iron supply to the oceans. Atmospheric Chemistry and Physics, 14(22): 12415-12428.

Jeong, G.Y. et al., 2014. Long-range transport of giant particles in Asian dust identified by physical, mineralogical, and meteorological analysis. Atmospheric Chemistry and Physics, 14(1): 505-521.

Jickells, T.D. et al., 2005. Global Iron Connections Between Desert Dust, Ocean Biogeochemistry, and Climate. Science, 308(5718): 67-71.

Journet, E., Desboeufs, K.V., Caquineau, S. and Colin, J.-L., 2008. Mineralogy as a critical factor of dust iron solubility. Geophysical Research Letters, 35(7).

Kallos, G., Kotroni, V., Lagouvardos, K. and Papadopoulos, A., 1998. On the long-range transport of air pollutants from Europe to Africa. Geophysical Research Letters, 25(5): 619-622.

Kandler, K. et al., 2009. Size distribution, mass concentration, chemical and mineralogical composition and derived optical parameters of the boundary layer aerosol at Tinfou, Morocco, during SAMUM 2006. Tellus B, 61(1).

Koçak, M., Kubilay, N., Herut, B. and Nimmo, M., 2005. Dry atmospheric fluxes of trace metals (Al, Fe, $\mathrm{Mn}, \mathrm{Pb}, \mathrm{Cd}, \mathrm{Zn}, \mathrm{Cu}$ ) over the Levantine Basin: A refined assessment. Atmospheric Environment, 39(38): 7330-7341.

Kok, J.F., 2011. A scaling theory for the size distribution of emitted dust aerosols suggests climate models underestimate the size of the global dust cycle. Proceedings of the National Academy of Sciences, 108(3): 1016-1021.

Lafon, S., Sokolik, I.N., Rajot, J.L., Caquineau, S. and Gaudichet, A., 2006. Characterization of iron oxides in mineral dust aerosols: Implications for light absorption. Journal of Geophysical Research: Atmospheres, 111(D21).

Mahowald, N.M. et al., 2005. Atmospheric global dust cycle and iron inputs to the ocean. Global Biogeochemical Cycles, 19(4).

Measures, C.I., Landing, W.M., Brown, M.T. and Buck, C.S., 2008. High-resolution Al and Fe data from the Atlantic Ocean CLIVAR-CO2 Repeat Hydrography A16N transect: Extensive linkages between atmospheric dust and upper ocean geochemistry. Global Biogeochemical Cycles, 22(1).

Mills, M.M., Ridame, C., Davey, M., La Roche, J. and Geider, R.J., 2004. Iron and phosphorus co-limit nitrogen fixation in the eastern tropical North Atlantic. Nature, 429(6989): 292-294.

Moore, C.M. et al., 2009. Large-scale distribution of Atlantic nitrogen fixation controlled by iron availability. Nature Geoscience, 2(12): 867-871.

Moreno, T. et al., 2006. Geochemical variations in aeolian mineral particles from the Sahara-Sahel Dust Corridor. Chemosphere, 65(2): 261-270.

Morton, P.L. et al., 2013. Methods for the sampling and analysis of marine aerosols: results from the 2008 GEOTRACES aerosol intercalibration experiment. Limnology and Oceanography: Methods, 11(2): 62-78. 
Muhs, D.R. et al., 2010. Geochemical and mineralogical evidence for Sahara and Sahel dust additions to Quaternary soils on Lanzarote, eastern Canary Islands, Spain. Terra Nova, 22(6): 399-410.

Muhs, D.R., Budahn, J.R., Prospero, J.M. and Carey, S.N., 2007. Geochemical evidence for African dust inputs to soils of western Atlantic islands: Barbados, the Bahamas, and Florida. Journal of Geophysical Research: Earth Surface, 112(F2).

Neuer, S. et al., 2004. Dust deposition pulses to the eastern subtropical North Atlantic gyre: Does ocean's biogeochemistry respond? Global Biogeochemical Cycles, 18(4).

Orians, K.J. and Bruland, K.W., 1986. The biogeochemistry of aluminum in the Pacific Ocean. Earth and Planetary Science Letters, 78(4): 397-410.

Potts, P.J., Thompson, M., Chenery, S.R.N., Webb, P.C. and Kasper, H.U., 2003. GEOPT13 - An international proficiency test for analytical geochemistry laboratories - report on round 13 / July 2003.

Prospero, J.M. and Carlson, T.N., 1972. Vertical and areal distribution of Saharan dust over the western equatorial north Atlantic Ocean. Journal of Geophysical Research, 77(27): 5255-5265.

Prospero, J.M. and Carlson, T.N., 1980. Saharan air outbreaks over the tropical North Atlantic. Pure and Applied Geophysics, 119(3): 677-691.

Prospero, J.M. and Lamb, P.J., 2003. African Droughts and Dust Transport to the Caribbean: Climate Change Implications. Science, 302(5647): 1024-1027.

Querol, X. et al., 2007. Source origin of trace elements in PM from regional background, urban and industrial sites of Spain. Atmospheric Environment, 41(34): 7219-7231.

Rijkenberg, M.J.A. et al., 2011. Environmental Forcing of Nitrogen Fixation in the Eastern Tropical and Sub-Tropical North Atlantic Ocean. PLoS ONE, 6(12).

Rijkenberg, M.J.A. et al., 2008. Changes in iron speciation following a Saharan dust event in the tropical North Atlantic Ocean. Marine Chemistry, 110(1-2): 56-67.

Rijkenberg, M.J.A. et al., 2012. Fluxes and distribution of dissolved iron in the eastern (sub-) tropical North Atlantic Ocean. Global Biogeochemical Cycles, 26(3).

Rodríguez, S. et al., 2011. Transport of desert dust mixed with North African industrial pollutants in the subtropical Saharan Air Layer. Atmospheric Chemistry and Physics, 11(13): 6663-6685.

Sarthou, G. et al., 2003. Atmospheric iron deposition and sea-surface dissolved iron concentrations in the eastern Atlantic Ocean. Deep Sea Research Part I: Oceanographic Research Papers, 50(1011): $1339-1352$.

Sarthou, G. et al., 2007. Influence of atmospheric inputs on the iron distribution in the subtropical North-East Atlantic Ocean. Marine Chemistry, 104(3-4): 186-202.

Schlosser, C. et al., 2014. Seasonal ITCZ migration dynamically controls the location of the (sub)tropical Atlantic biogeochemical divide. Proceedings of the National Academy of Sciences, 111(4): 14381442.

Schroth, A.W., Crusius, J., Sholkovitz, E.R. and Bostick, B.C., 2009. Iron solubility driven by speciation in dust sources to the ocean. Nature Geoscience, 2(5): 337-340.

Schütz, L. and Sebert, M., 1987. Mineral aerosols and source identification. Journal of Aerosol Science, 18(1): 1-10.

Shelley, R.U., Morton, P.L. and Landing, W.M., Elemental ratios and enrichment factors in aerosols from the US-GEOTRACES North Atlantic transects. Deep Sea Research Part II: Topical Studies in Oceanography. 
Shi, Z., Shao, L., Jones, T.P. and Lu, S., 2005. Microscopy and mineralogy of airborne particles collected during severe dust storm episodes in Beijing, China. Journal of Geophysical Research: Atmospheres, 110(D1).

Sholkovitz, E.R., Sedwick, P.N., Church, T.M., Baker, A.R. and Powell, C.F., 2012. Fractional solubility of aerosol iron: Synthesis of a global-scale data set. Geochimica et Cosmochimica Acta, 89: 173189.

Stuut, J.-B. et al., 2005. Provenance of present-day eolian dust collected off NW Africa. Journal of Geophysical Research: Atmospheres, 110(D4).

Taylor, S.R. and Gorton, M.P., 1977. Geochemical application of spark source mass spectrography--III. Element sensitivity, precision and accuracy. Geochimica Et Cosmochimica Acta, 41(9): 13751380.

Taylor, S.R. and McLennan, S.M., 1995. The geochemical evolution of the continental crust. Reviews of Geophysics, 33(2): 241-265.

Trapp, J.M., Millero, F.J. and Prospero, J.M., 2010. Temporal variability of the elemental composition of African dust measured in trade wind aerosols at Barbados and Miami. Marine Chemistry, 120(14): 71-82.

Ussher, S.J. et al., 2013. Impact of atmospheric deposition on the contrasting iron biogeochemistry of the North and South Atlantic Ocean. Global Biogeochemical Cycles, 27(4): 1096-1107.

Weaver, C.E., 1989. Clays, Muds and Shales. Elsevier, 820 pp. 


\section{Highlights}

Aerosol time-series measurements on the Cape Verde reveal seasonal variations

High aerosol loadings in winter at Cape Verde related to dust transport in trade winds

Dust supply during summer originating mainly from the Sahel region

Dust supply during winter originating mainly from the North and West Saharan region

Clay dominant mineral in aerosols over Cape Verde, influencing iron solubility 